Article

\title{
Synthesis and Evaluation of Novel 2,2-Dimethylthiochromanones as Anti-Leishmanial Agents
}

\author{
Seán Coll ${ }^{1}$, Mohammad Alhazmi ${ }^{1}$, Patrícia de Aguiar Amaral ${ }^{2}$, Sandra Bourgeade-Delmas ${ }^{3}$, \\ Anne-Cécile Le Lamer ${ }^{3}$ and James W. Barlow $1, * \mathbb{D}$
}

1 Department of Chemistry, RCSI University of Medicine and Health Sciences, 123 St. Stephen's Green, Dublin 2, Ireland; seancoll@rcsi.ie (S.C.); malhazmi@rcsi.ie (M.A.)

2 Laboratory of Medicinal Plants (LaPlaM/PPGCA), Universidade do Extremo Sul Catarinense (UNESC), Avenida Universitária 1105, Bairro Universitário, Criciúma 88806-000, SC, Brazil; amaral@unesc.net

3 UMR 152 IRD-UPS PHARMADEV, Faculté des Sciences Pharmaceutiques, Université Toulouse III-Paul Sabatier, 35 Chemin des Maraîchers, 31062 Toulouse CEDEX 09, France; sandra.bourgeade-delmas@ird.fr (S.B.-D.); anne-cecile.le-lamer@univ-tlse3.fr (A.-C.L.L.)

* Correspondence: jambarlow@rcsi.ie; Tel.: +353-1-4028-520

Citation: Coll, S.; Alhazmi, M.; de Aguiar Amaral, P.;

Bourgeade-Delmas, S.; Le Lamer, A.-C.; Barlow, J.W. Synthesis and Evaluation of Novel

2,2-Dimethylthiochromanones as Anti-Leishmanial Agents. Molecules 2021, 26, 2209

https://doi.org/10.3390/molecules 26082209

Academic Editors: Elisa Ovidi and Antonio Tiezzi

Received: 28 February 2021

Accepted: 9 April 2021

Published: 12 April 2021

Publisher's Note: MDPI stays neutra with regard to jurisdictional claims in published maps and institutional affiliations.

Copyright: (c) 2021 by the authors. Licensee MDPI, Basel, Switzerland. This article is an open access article distributed under the terms and conditions of the Creative Commons Attribution (CC BY) license (https:// creativecommons.org/licenses/by/ $4.0 /)$.

\begin{abstract}
Within this work, we describe the design and synthesis of a range of novel thiochromanones based on natural products reported to possess anti-leishmanial action, and their synthetic derivatives. All compounds were elaborated via the key intermediate 2,2,6-trimethoxythiochromanone, which was modified at the benzylic position to afford various ester, amine and amide analogues, substituted by chains of varying lipophilicity. Upon testing in Leishmania, $\mathrm{IC}_{50}$ values revealed the most potent compounds to be phenylalkenyl and haloalkyl amides 11a and 11e, with $\mathrm{IC}_{50}$ values of 10.5 and $7.2 \mu \mathrm{M}$, respectively.
\end{abstract}

Keywords: thiochromanone; uniflorol; gibbilimbol; Leishmania

\section{Introduction}

Leishmaniasis refers to a spectrum of diseases due to infection with one of a number of protozoal species within the genus Leishmania, transmitted through the bite of infected sandflies. Historically, it has been widespread in tropical climates across many continents. In humans, Leishmania parasites replicate intracellularly and patients classically present with either visceral or cutaneous disease [1]. Available treatments suffer from disadvantages including toxicity, formulation challenges and a lack of oral dosage forms. Of particular concern, resistance to all common agents, namely pentavalent antimonials, pentamidine, miltefosine, paromomycin and amphotericin B has been documented [2]. Therefore, novel approaches to prevent and treat Leishmania require an ongoing research focus. In this context, small molecule therapies remain affordable and druggable approaches, with significant anti-parasitic activity demonstrated for several compounds, encompassing natural products such as oxygenated heterocycles and alkenylphenols, and their synthetic isosteres (Figure 1). Examples include the chromanone uniflorols 1-2 of Calea spp, which inhibited L. major promastigote growth by 55-89\% between $25-100 \mu \mathrm{g} / \mathrm{mL}$ [3]. Synthetic derivatization of these compounds with the aim of improving stability and activity resulted in the synthesis of 3, which inhibited axenic amastigotes and intracellular amastigotes of L. infantum with $\mathrm{IC}_{50}$ values of 25.3 and $24.6 \mu \mathrm{M}$ respectively [4]. This compound is notable for possessing a lipophilic aminoalkyl chain para to the chromanone oxygen. Considering this structural scaffold, parallels emerge to the observations of Varela et al. [5], who prepared a range of synthetic phenolic derivatives based on the alkenylphenol gibbilimbol B, 4, a natural product isolated from Piper malacophyllum by de Oliveira and colleagues [6], who noted that it possessed leishmanicidal activity. Subsequent papers by Varela and colleagues have expanded the structure-activity relationships around this compound, with 
the aim of improving selectivity and solubility, while maintaining anti-parasitic activity. Of the various analogues prepared to date, methyl ether $\mathbf{5}$, bearing a para-octanoyl chain, displayed high activity against amastigotes of both L. infantum and Trypanosoma cruzi, with $\mathrm{IC}_{50}$ values of 1.3 and $5.8 \mu \mathrm{M}$ respectively [7].<smiles>C=CC=C(CO)C(=O)OC(C)c1ccc2c(c1)C(=O)CC(C)(C)O2</smiles><smiles>CCCCCCCCNCc1ccc2c(c1)C(=O)CC(C)(C)O2</smiles>

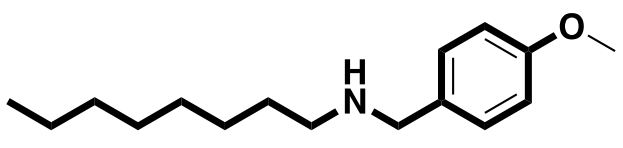

Figure 1. Natural products with activity against Leishmania and their synthetic analogues.

In addition to these structures, other groups have probed the anti-leishmanial activity of related synthetic heterocycles. One notable example is the thiochromanone class (Figure 2), the sulfur analogues of chromanones such as 1-3. Thiochromanones represent an interesting group from a medicinal chemistry perspective, with examples known to display anti-fungal [8], anti-cancer [9] or anti-trypanosomal [10] activities. In the context of Leishmania, certain thiochromanone derivatives containing either semicarbazone, thiosemicarbazone or triazine nitrile warheads were developed as specific cysteine protease B inhibitors [11]. In more recent work, Vargas and colleagues [12] prepared several thiochromanones modified at ring positions 2 and 6 . Upon testing against $L$. (V) panamensis, active compounds such as 6 were those bearing a vinyl sulfone moiety and a phenyl moiety at $C-2$, with $\mathrm{EC}_{50}$ values $<10 \mu \mathrm{M}$ and a selectivity index of over 100 for some compounds. Within this series of compounds, activity decreased upon removal of either the double bond or the sulfone moiety. The same group later published further results on the activity of acyl hydrazone derivatives of thiochromanones against the same leishmanial species [13]. Such derivatization significantly enhanced anti-leishmanial activity, with semicarbazone and thiosemicarbazone derivatives of thioflavanone displaying the highest activities, with 7 displaying an $\mathrm{EC}_{50}$ value of $5.1 \mu \mathrm{M}$, with low cytotoxicity. Thiochroman hydrazides without C-2 substitution were separately evaluated by Zapata et al. [14], who studied topical application of 8 co-formulated with saponins, and this combination proved very effective against parasite survival (L. braziliensis \& L. pifanoi) and infectivity. Most recently, Ortiz et al. [15] published an evaluation of the activity of various thiochromenes, thichromanones and hydrazones with $C-2$ or $C-3$ carbonyl or carboxyl substitutions against intracellular amastigotes of $L$. $(V)$ panamensis. A number of compounds, notably of structural type 9 , had $\mathrm{EC}_{50}$ values below $10 \mu \mathrm{M}$, but clear structure-activity relationships were not discerned. 
<smiles>O=C1C=C(c2ccc(C(F)(F)F)cc2)S(=O)(=O)c2cc(F)ccc21</smiles><smiles>NC(=S)NN=C1CC(c2ccccc2)Sc2ccccc21</smiles><smiles>O=C(NN=C1CCSc2ccccc21)c1ccccc1</smiles><smiles>[R]C1=C(C(C)=O)C(CCCCC)Sc2ccccc21</smiles>

Figure 2. Thiochromanones with activity against Leishmania.

Given the interesting activities of the chromanones and thiochromanones described in the literature against Leishmania species, we resolved to prepare thio analogues of the known anti-leishmanial chromanones 1-3 (Figure 3). We envisaged ester 10 and amide 11 derivatives, which incorporate either a benzylester or benzylamido linkage para to the thiochromanone sulfur. We also sought to vary the amido functionality by replacing it with a more basic alkylamino chain, as seen in 12 . These compounds represent both sulfur analogues of chromanone 3 and also derivatives of the potent gibbilimbol ether 5 , within a thiochromanone framework. To investigate the impact of variant oxidation states of sulfur, we envisaged compounds 13 and 14.<smiles>CC(=O)OCc1ccc2c(c1)C(=O)CC(C)(C)S2</smiles>

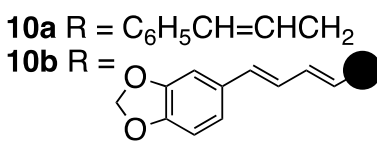<smiles>CCCCCCNC(=O)Cc1ccc2c(c1)C(=O)CC(C)(C)S2</smiles>

11a $\mathrm{R}=\mathrm{C}_{6} \mathrm{H}_{5} \mathrm{CH}=\mathrm{CHCH}_{2}$ 11b $\mathrm{R}=\mathrm{C}_{6} \mathrm{H}_{5} \mathrm{CH}=\mathrm{CH}\left(\mathrm{CH}_{2}\right)_{3}$ $11 \mathrm{c} R=$<smiles>CC=CC=Cc1ccc2c(c1)OCO2</smiles>

11d $\mathrm{R}=\mathrm{C}_{7} \mathrm{H}_{15}$ 11e $\mathrm{R}=\mathrm{C}_{8} \mathrm{H}_{16} \mathrm{Br}$<smiles>[R]NCc1ccc2c(c1)C(=O)CC(C)(C)S2</smiles>

12a $\mathrm{R}=\mathrm{C}_{4} \mathrm{H}_{9}$ 12b $\mathrm{R}=\mathrm{C}_{6} \mathrm{H}_{13}$ 12c $\mathrm{R}=\mathrm{C}_{8} \mathrm{H}_{17}$ 12d $\mathrm{R}=\mathrm{C}_{10} \mathrm{H}_{21}$<smiles>CCCCCCCCNCc1ccc2c(c1)C(=O)CC(C)(C)S2(=O)=O</smiles>

Figure 3. Synthetic targets based on lead compounds 1-3.

\section{Results}

\subsection{Chemistry}

Construction of thiochromanone skeletons may follow one of a number of approaches, including Pd-catalyzed carbonylative heteroannulation of iodothiophenols with allenes and carbon monoxide, base-catalyzed cyclization of $\beta$-halopropanoic acids with arylthiophenols, base-catalyzed condensation of $\beta$-propiolactone with 2-ethylthiophenol followed by acid-promoted cyclization, and intramolecular Friedel-Crafts acylation with Lewis acids or methanesulfonic acid [16]. A recently described one-pot procedure employs a microwave-assisted protocol for the synthesis of 2-/3-methylthiochroman-4-ones by superacid-catalyzed alkylation followed by cyclic acylation [17]. However, preparation of the more hindered 2,2-dimethyl-substituted analogues is more challenging than either un- or mono-substituted C-2 analogues, and protocols such as base-catalyzed cyclization afforded very low yields in our preliminary experiments. Attempts at superacid-catalyzed reactions were entirely unsuccessful. Ultimately, we utilised the established Friedel-Crafts heterocyclisation of commercial thiophenol 15 with 3,3-dimethylacrylic acid in methanesulfonic acid [18], to afford thiochromanone 16 (Scheme 1). Oxidation using persulfate afforded the benzylic aldehyde 17, easily separable from the side-product sulfoxide. Bioreduction using Daucus carota cleanly afforded 18, which was esterified with appropriate 
acids using the coupling agent 1-ethyl-3-(3'-dimethylaminopropyl)carbodiimide hydrochloride (EDC) under basic conditions.<smiles>Cc1ccc(S)cc1</smiles><smiles>CC=CC=Cc1ccc2c(c1)OC(P)O2</smiles>

Scheme 1. Synthesis of compounds 10a,b. Reagents and conditions: (i) $\left(\mathrm{CH}_{3}\right)_{2} \mathrm{C}=\mathrm{CHCOOH}, \mathrm{MeSO}_{3} \mathrm{H}, 80{ }^{\circ} \mathrm{C}, 8 \mathrm{~h}$; (ii) $\mathrm{K}_{2} \mathrm{~S}_{2} \mathrm{O}_{8}$, $\mathrm{CuSO}_{4}, \mathrm{H}_{2} \mathrm{O} / \mathrm{CH}_{3} \mathrm{CN}$ (1:1), 75-80 ${ }^{\circ} \mathrm{C}, 1 \mathrm{~h}$; (iii) D. carota, RT, $72 \mathrm{~h}$; (iv) Appropriate acid, EDC, Et 3 N, DCM, $0{ }^{\circ} \mathrm{C}-\mathrm{RT}, 24-72 \mathrm{~h}$.

For amide series 11 (Scheme 2), benzylic bromination of $\mathbf{1 6}$ with $\mathrm{N}$-bromosuccinimide (NBS) afforded 19 in good yield, analogous to the conditions employed for the chromanone analogue [4]. Nucleophilic substitution with sodium azide proceeded smoothly to azide 20, which was reduced either under a Staudinger protocol or via zinc powder in aqueous media to afford amine 21. Amidation of the primary amine nitrogen was achieved using EDC coupling with the appropriate acid under basic conditions.

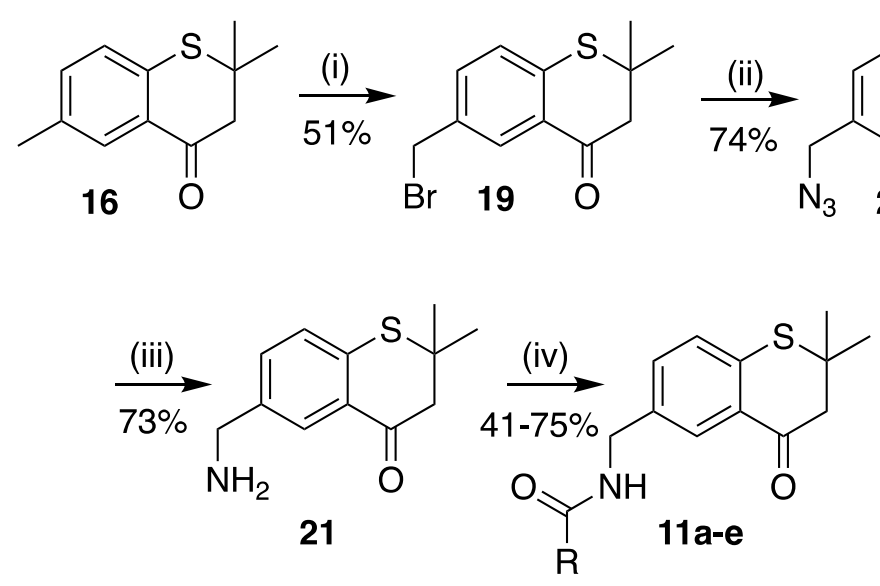<smiles>[B]=N[14CH2]/C=C\C=C\c1ccc2c(c1)OCO2</smiles>

Scheme 2. Synthesis of compounds 11a-e. Reagents and conditions: (i) NBS, dibenzoyl peroxide, cyclohexane, $95-100{ }^{\circ} \mathrm{C}, 8 \mathrm{~h}$; (ii) $\mathrm{NaN}_{3}, \mathrm{DMF}, 50{ }^{\circ} \mathrm{C}, 3 \mathrm{~h}$; (iii) $\mathrm{PPH}_{3}, \mathrm{THF} / \mathrm{H}_{2} \mathrm{O}$ (10:1), RT, 12 h; (iv) RCOOH, EDC, Et 3 N, RT, 24 h.

In parallel, amine series 12 was prepared (Scheme 3) via substitution of bromide synthon 19 in refluxing acetonitrile, or by first oxidising 16 to aldehyde 17 before reductive amination with sodium triacetoxyborohydride (STAB). Direct coupling of the bromide with primary amines proceeded almost instantaneously, yet required careful stoichiometric control and subsequent chromatography to avoid residual contaminating amine. On the other hand, particularly for the higher-boiling alkylamines, reductive amination proved 
more favourable, with the stable intermediate imine 22 being purified prior to regioselective reduction with one equivalent of sodium borohydride.<smiles>Cc1ccc2c(c1)C(=O)CC(C)(C)S2</smiles><smiles>C[14CH3]</smiles><smiles>CC1(C)CC(=O)c2cc(CBr)ccc2S1</smiles>

19<smiles>CNC(c1ccc2c(c1)C(=O)CC(C)(C)S2)[13C](C)(C)C</smiles>
12a-d 12a: $\mathrm{n}=1$ 12b: $n=3$ 12c: $\mathrm{n}=5$ 12d: $n=7$

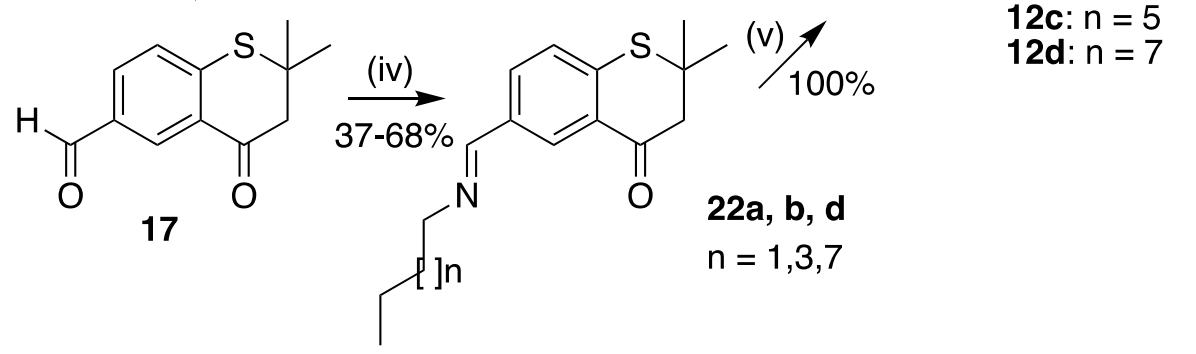

Scheme 3. Synthesis of compounds 12a-d. Reagents and conditions: (i) NBS, dibenzoyl peroxide, cyclohexane, $95-100{ }^{\circ} \mathrm{C}, 8 \mathrm{~h}$; (ii) Alkylamine, $\mathrm{CH}_{3} \mathrm{CN}, \Delta, 6 \mathrm{~h}$; (iii) $\mathrm{K}_{2} \mathrm{~S}_{2} \mathrm{O}_{8}, \mathrm{CuSO}_{4}, \mathrm{H}_{2} \mathrm{O} / \mathrm{CH}_{3} \mathrm{CN}$ (1:1), 75-80 ${ }^{\circ} \mathrm{C}, 1 \mathrm{~h}$; (iv) Alkylamine, STAB, $\mathrm{CH}_{3} \mathrm{COOH}$, THF/DCM, RT, 24 h; (v) $\mathrm{NaBH}_{4}, \mathrm{MeOH}, \mathrm{RT}, 1 \mathrm{~h}$.

To provide sulfur oxides 13 and 14, successive oxidations of 16 were envisaged. Although perborate-catalyzed oxidation of $\mathbf{1 6}$ afforded both sulfoxide 23 and sulfone 24 products (Scheme 4), further reaction with persulfate did not proceed. Under bromination conditions with NBS, in the case of 23 , decomposition occurred, while alpha bromination of $\mathbf{2 4}$ occurred with no accompanying benzylic bromination. Protection of the secondary nitrogen in $\mathbf{1 2 c}$ with a BOC group prior to oxidation with hydrogen peroxide in the presence of Montmorillonite K10 [19] obtained sulfoxide 27a. Likewise, perborate oxidation of $\mathbf{2 6}$ in glacial acetic acid (GAA) [20] afforded $\mathbf{2 7 b}$. Deprotection of these BOC-amides afforded the respective sulfoxide $\mathbf{1 3}$ and sulfone $\mathbf{1 4}$.<smiles>Cc1ccc2c(c1)C(=O)CC(C)(C)S2(C)C(C)(C)C</smiles>
$24 \%$ $64 \%$<smiles></smiles><smiles>CCCCNCc1ccc2c(c1)C(=O)CC(C)(C)S2</smiles>

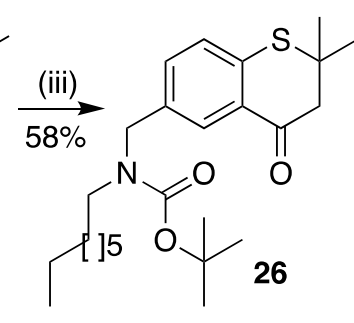

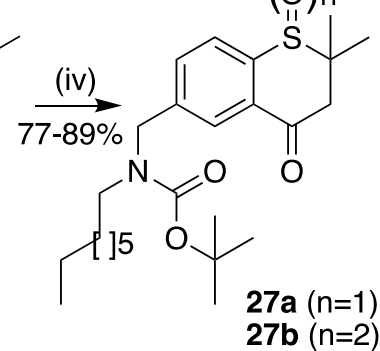

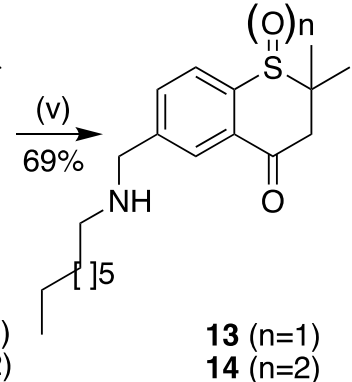

Scheme 4. Synthesis of compounds 13 and 14. Reagents and conditions: (i) $\mathrm{NaBO}_{3} \cdot 4 \mathrm{H}_{2} \mathrm{O}, \mathrm{GAA}, 55^{\circ} \mathrm{C}, 4 \mathrm{~h}$; (ii) NBS, dibenzoyl peroxide, cyclohexane, $95-100{ }^{\circ} \mathrm{C}, 8 \mathrm{~h}$; (iii) $\mathrm{Boc}_{2} \mathrm{O}$, DCM, RT, $12 \mathrm{~h}$; (iv) $35 \% \mathrm{H}_{2} \mathrm{O}_{2}$, Montmorillonite K10, RT, $12 \mathrm{~h}$ or $\mathrm{NaBO}_{3} \cdot 4 \mathrm{H}_{2} \mathrm{O}, \mathrm{GAA}, 55^{\circ} \mathrm{C}, 4 \mathrm{~h}$; (v) TFA, DCM, $0{ }^{\circ} \mathrm{C}-\mathrm{RT}, 24 \mathrm{~h}$. 


\subsection{Computational Study}

Simple molecular descriptors were calculated using the Molinspiration online property calculation toolkit (http:/ / www.molinspiration.com, accessed on 1 February 2021). Results are shown in Table 1.

Table 1. Calculations of molecular properties of synthesised compounds using Molinspiration.

\begin{tabular}{|c|c|c|c|c|c|c|c|c|}
\hline Compound & $\operatorname{miLog} P$ & TPSA & nAtoms & MW & nON & nOHNH & nRotb & Vol. $\left(\mathrm{A}^{3}\right)$ \\
\hline $10 a$ & 4.91 & 43.38 & 26 & 366.48 & 3 & 0 & 6 & 337.14 \\
\hline $10 \mathrm{~b}$ & 5.36 & 61.84 & 30 & 422.50 & 5 & 0 & 6 & 371.68 \\
\hline 11a & 4.26 & 46.17 & 26 & 365.50 & 3 & 1 & 5 & 340.56 \\
\hline $11 b$ & 5.28 & 46.17 & 28 & 393.55 & 3 & 1 & 7 & 374.16 \\
\hline 11c & 4.40 & 64.64 & 30 & 421.52 & 5 & 1 & 5 & 375.10 \\
\hline 11d & 5.10 & 46.17 & 24 & 347.52 & 3 & 1 & 8 & 342.30 \\
\hline $11 \mathrm{e}$ & 5.45 & 46.17 & 26 & 440.45 & 3 & 1 & 10 & 377.23 \\
\hline $12 a$ & 3.76 & 29.10 & 19 & 277.43 & 2 & 1 & 5 & 272.91 \\
\hline $12 b$ & 4.77 & 29.10 & 21 & 305.49 & 2 & 1 & 7 & 306.51 \\
\hline $12 \mathrm{c}$ & 5.78 & 29.10 & 23 & 333.54 & 2 & 1 & 9 & 340.12 \\
\hline $12 d$ & 6.79 & 29.10 & 25 & 361.60 & 2 & 1 & 11 & 373.72 \\
\hline 13 & 4.19 & 46.17 & 24 & 349.54 & 3 & 1 & 9 & 347.67 \\
\hline 14 & 4.66 & 63.24 & 25 & 365.54 & 4 & 1 & 9 & 353.42 \\
\hline 3 & 5.40 & 38.33 & 23 & 317.47 & 3 & 1 & 9 & 330.98 \\
\hline
\end{tabular}

\subsection{Pharmacological Activity}

Selected compounds were evaluated for their leishmanicidal ability as previously described [21], through examining their activity on L. infantum axenic amastigotes, and the results are expressed in Table 2 as $\mathrm{IC}_{50}$ values. In parallel, evaluation of the cytotoxicity of test compounds was performed by MTT assay using the J774A.1 macrophage cell line. Results are presented as $\mathrm{CC}_{50}$ values.

Table 2. Activity of thiochromanones against Leishmania amastigotes and evaluation of cytotoxicity.

\begin{tabular}{|c|c|c|c|}
\hline Compound & $\begin{array}{l}\text { L. infantum } \\
\mathrm{IC}_{50}(\mu \mathrm{M})^{1}\end{array}$ & $\begin{array}{c}\text { J774A.1 } \\
\mathrm{CC}_{50}(\mu \mathrm{M})^{1}\end{array}$ & S.I. ${ }^{2}$ \\
\hline $10 a$ & $34.4(2.76)$ & $>136.43$ & $>3.97$ \\
\hline $10 \mathrm{~b}$ & $91.3(0.47)$ & $22.53(2.32)$ & 0.25 \\
\hline $11 a$ & $10.5(1.12)$ & $31.63(1.56)$ & 3.01 \\
\hline $11 b$ & $19.9(2.01)$ & $14.03(1.63)$ & 0.71 \\
\hline 11c & $>118.62$ & $>118.62$ & $\mathrm{ND}^{3}$ \\
\hline 11d & $51.3(3.45)$ & $137.46(6.68)$ & 2.68 \\
\hline $11 \mathrm{e}$ & $7.20(0.34)$ & $58.01(2.31)$ & 8.06 \\
\hline $12 a$ & $26.5(0.79)$ & 33.23 (3.97) & 1.25 \\
\hline $12 b$ & $23.1(0.85)$ & $25.76(2.42)$ & 1.12 \\
\hline $12 c$ & $19.5(1.41)$ & $22.64(1.68)$ & 1.16 \\
\hline
\end{tabular}


Table 2. Cont.

\begin{tabular}{|c|c|c|c|}
\hline Compound & $\begin{array}{l}\text { L. infantum } \\
\mathrm{IC}_{50}(\mu \mathrm{M})^{1}\end{array}$ & $\begin{array}{c}\text { J774A.1 } \\
\mathrm{CC}_{50}(\mu \mathrm{M})^{1}\end{array}$ & S.I. ${ }^{2}$ \\
\hline $12 d$ & $12.4(0.88)$ & $23.12(0.33)$ & 1.86 \\
\hline 13 & $33.4(2.72)$ & $40.91(3.06)$ & 1.22 \\
\hline 14 & $33.8(1.56)$ & $42.76(5.96)$ & 1.27 \\
\hline Amphotericin B & $0.072(0.011)$ & & \\
\hline Doxorubicin & & $0.047(0.004)$ & \\
\hline
\end{tabular}

${ }^{1}$ Results are reported as the mean value \pm standard deviation of the half-maximum concentration in $\mu \mathrm{M} .{ }^{2}$ SI $($ Selectivity Index) $=$ $\mathrm{CC}_{50} / \mathrm{IC}_{50} \cdot{ }^{3}$ Non-determinable.

\section{Discussion}

Thirteen novel thiochromanone analogues were synthesised in this work, all esters $(\mathbf{1 0 a}, \mathbf{b})$, amides $(\mathbf{1 1 a}-\mathbf{e})$ or amines $(\mathbf{1 2 a}-\mathbf{d}, \mathbf{1 3}, \mathbf{1 4})$ at the 6-position of a 2,2-dimethylthiochromanome core.

To obey Lipinski's rule, orally active drugs should have: (a) no more than 5 hydrogen bond donors (n-OHNH); (b) no more than 10 hydrogen acceptors (n-ON); (c) an octanolwater partition coefficient $(\log \mathrm{P})$ not $>5$; and $(\mathrm{d})$ a molecular weight $<500 \mathrm{Da}$. Of our synthesised compounds, seven fulfilled Lipinski's rule, with six each showing one violation. Rotatable bond count (nRotb), molecular volume (Vol.) and topological polar surface area (TPSA) were also calculated for the compounds. Molecular volume is a function of molecular weight and structure and considers all accessible conformations available to the molecule under physiological conditions, and alongside TPSA, is used to predict drug transport properties. Drugs of poor bioavailability and absorption have high TPSA values. Our compounds had TPSA values ranging from 29 to 65, with compound 12c, the thio isostere of 3 showing predicted improved bioavailabilty with a lower TPSA score.

Compounds 10a and $\mathbf{1 0 b}$ are ester derivatives of previously synthesised chromanone esters, and while both compounds showed activity against $L$. infantum, styryl ester 10a was three-fold more active, with an $\mathrm{IC}_{50}$ of $34.4 \mu \mathrm{M}$. As the ester moiety of these molecules is susceptible to hydrolysis, we prepared series 11, a group of amides. A comparison of the activity of 10a and 11a revealed that the amide analogue was over three times more active than the ester against $L$. infantum, perhaps reflecting the expected better stability profile. However, piperamide 11c was devoid of activity. Within amides 11, extending the lipophilic chain of 11a by two carbons, as in 11b, halved activity (10.5 vs. $19.9 \mu \mathrm{M})$. While a linear octanoyl chain in 11d reduced activity 5 -fold compared to the styryl derivative, the haloalkyl unit in 11e resulted in the most active compound ( $\left.\mathrm{IC}_{50} 7.2 \mu \mathrm{M}\right)$, superior to the phenylalkenyl derivative 11a. Within the alkylamide compounds 12a-d, extension of the lipophilic carbon chain by two atoms each time correlated with an increase in activity, with the decylamine derivative $\mathbf{1 2 d}$ having an $\mathrm{IC}_{50}$ of $12.4 \mu \mathrm{M}$. Compound $\mathbf{1 2 c}$ ( $\mathrm{IC}_{50}$ $19.5 \mu \mathrm{M}$ ) represents the thio isostere of the previously reported 3, which inhibited axenic amastigotes of $L$. infantum with an $\mathrm{IC}_{50}$ of $25.3 \mu \mathrm{M}$, suggesting that the sulfur atom results in a moderate improvement in activity. However, we must note the cytotoxicity of some of the compounds, notably $\mathbf{1 1} \mathbf{b}$ and alkylamines $\mathbf{1 2}$, which although showing interesting activity against axenic amastigotes, were comparably cytotoxic to macrophages. Structures with similarity to compounds $\mathbf{4}$ and $\mathbf{5}$ may have effects as membrane disruptors; this needs further exploration within our series of compounds to try and optimise promising anti-leishmanial activity but without appreciable toxicity. Additional work should involve exploration of likely mechanisms of action, such as inhibition of pteridine reductase 1 (PTR1), a proposed mechanism of action of analogous chroman-4-one derivatives [22,23]. In conclusion, compounds 11a and 11e represent interesting compounds, with notable anti-leishmanial activity and good selectivity. 


\section{Materials and Methods \\ 4.1. Chemistry}

All required chemicals, solvents, and reagents were purchased from Sigma-Aldrich (Arklow, Ireland) and were of reagent grade. Reaction progress was monitored on precoated thin layer chromatographic aluminum sheets (silica gel 60 F254, Merck, Carrigtwohill, Ireland), and TLC visualization was done using a UV lamp. Fourier transform infrared spectra were carried out with neat film coated samples on diamond using a Nicolet ${ }^{\mathrm{TM}}$ iS ${ }^{\mathrm{TM}} 10$ FT-IR spectrophotometer (Thermo Fisher, Dublin, Ireland). Significant absorption peak (vmax) values are given in $\mathrm{cm}^{-1} \cdot{ }^{1} \mathrm{H}$ - and ${ }^{13} \mathrm{C}$-NMR spectra were recorded on an Avance 400 spectrometer (Bruker, Rheinstetten, Germany) at $400 \mathrm{MHz}$ and $100 \mathrm{MHz}$, respectively, in $\mathrm{CDCl}_{3}$ and $\mathrm{CD}_{3} \mathrm{OD}$, using tetramethylsilane (TMS) as the internal standard (Spectra available in Supplementary Materials). Chemical shift values are given on the $\delta$ (ppm) scale, with signals described as follows: s (singlet), d (doublet), dd (double doublet), $\mathrm{t}$ (triplet), $\mathrm{q}$ (quartet), br. (broad signal), $\mathrm{m}$ (multiplet), and coupling constants $(J)$ expressed in Hz. Mass spectral analyses were recorded using a LCT Premiere XE (ESI-TOF MS) instrument (Waters, Dublin, Ireland). All calculated exact mono isotopic mass distributions were calibrated against internal reference standards.

\section{2,2,6-Trimethylthiochroman-4-one (16)}

This compound was prepared and characterized as previously described [17]. Yield: 33\%.

\section{2,2-Dimethyl-4-oxothiochromane-6-carbaldehyde (17)}

To a solution of $\mathbf{1 6}(0.53 \mathrm{~g}, 2.57 \mathrm{mmol})$ in acetonitrile $(15 \mathrm{~mL})$ was added a solution of potassium persulfate $(1.39 \mathrm{~g}, 5.14 \mathrm{mmol})$ in water $(15 \mathrm{~mL})$, and copper sulfate $(0.13 \mathrm{~g}$, $0.52 \mathrm{mmol}$ ). The resulting solution was stirred at $75-80{ }^{\circ} \mathrm{C}$ for $1 \mathrm{~h}$ and then cooled. The cold mixture was diluted with saturated sodium bicarbonate solution and extracted with diethyl ether $(3 \times 50 \mathrm{~mL})$. The diethyl ether extracts were concentrated in vacuo and the residue purified by flash chromatography (pet. ether/EtOAc 10:1) to give $\mathbf{1 7}$ as a pale oil that solidified on standing $(70 \mathrm{mg}, 12 \%) .{ }^{1} \mathrm{H}-\mathrm{NMR}\left(\mathrm{CDCl}_{3}\right) \delta_{\mathrm{H}} 1.43\left(6 \mathrm{H}, \mathrm{s}, \mathrm{C}\left(\mathrm{C}_{3}\right)_{2}\right), 2.86(2 \mathrm{H}, \mathrm{s}$, $\left.\mathrm{C}_{2}\right), 7.30(1 \mathrm{H}, \mathrm{d}, J=8.2 \mathrm{~Hz}, \mathrm{Ar} \underline{\mathrm{H}}), 7.84(1 \mathrm{H}, \mathrm{d}, J=7.9 \mathrm{~Hz}, \mathrm{Ar} \underline{\mathrm{H}}), 8.47(1 \mathrm{H}, \mathrm{s}, \underline{\mathrm{H}} 5), 9.90(1 \mathrm{H}$, $\mathrm{s}, \mathrm{C} \underline{\mathrm{HO}}) .{ }^{13} \mathrm{C}-\mathrm{NMR} \delta_{\mathrm{C}} 28.6\left(\left(\underline{\mathrm{CH}}_{3}\right)_{2}\right), 45.3\left(\underline{\mathrm{C}}\left(\mathrm{CH}_{3}\right)_{2}\right), 53.2\left(\underline{\mathrm{C}} \mathrm{H}_{2}\right), 128.4(\mathrm{Ar} \underline{\mathrm{CH}}), 129.6(\mathrm{Ar} \underline{\mathrm{C}})$,

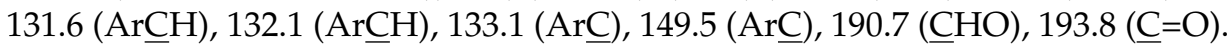

\section{6-(Hydroxymethyl)-2,2-dimethylthiochroman-4-one (18)}

To $17(70 \mathrm{mg}, 0.032 \mathrm{mmol})$ in DMF $(1 \mathrm{~mL})$ was added distilled water $(50 \mathrm{~mL})$ and freshly cut slices of $D$. carota $(10 \mathrm{~g})$. The resulting mixture was stirred vigorously at room temperature for $72 \mathrm{~h}$. The reaction was filtered, and the filtrate washed with ethyl acetate $(50 \mathrm{~mL})$. The water/ethyl acetate mixture was separated, and the ethyl acetate extract dried over $\mathrm{Na}_{2} \mathrm{SO}_{4}$. The crude orange oil was purified by flash column chromatography (pet. ether/EtOAc 7:1) to afford alcohol 18, (54 mg, 76\%). ${ }^{1} \mathrm{H}-\mathrm{NMR}\left(\mathrm{CDCl}_{3}\right) \delta_{\mathrm{H}} 1.47\left(6 \mathrm{H}, \mathrm{s}, \mathrm{CH}_{3}\right)$, $2.88\left(2 \mathrm{H}, \mathrm{s}, \mathrm{C}_{2}\right), 4.69\left(2 \mathrm{H}, \mathrm{s}, \mathrm{C}_{2} \mathrm{OH}\right), 5.30(1 \mathrm{H}, \mathrm{s}, \mathrm{O} \underline{\mathrm{H}}), 7.24(1 \mathrm{H}, \mathrm{d}, \mathrm{Ar} \underline{\mathrm{H}}), 7.46(1 \mathrm{H}, \mathrm{dd}$, $J=8.3,1.7 \mathrm{~Hz}, \mathrm{Ar} \underline{\mathrm{H}}), 8.08(1 \mathrm{H}, \mathrm{s}, \underline{\mathrm{H}} 5)$.

\section{(2,2-Dimethyl-4-oxothiochroman-6-yl)methyl (E)-4-phenylbut-3-enoate (10a)}

To a solution of trans-styrylacetic acid $(15 \mathrm{mg}, 0.09 \mathrm{mmol})$ in dichloromethane $(5 \mathrm{~mL})$ was added EDC-HCl (30 mg, $0.16 \mathrm{mmol}$ ) and 4-(dimethylamino)pyridine (DMAP) (2 mg). To this solution was added $18(20 \mathrm{mg}, 0.09 \mathrm{mmol})$. The reaction was stirred for $72 \mathrm{~h}$ at room temperature. The residual solvent was removed in vacuo, and the crude residue purified by flash column chromatography (pet. ether/EtOAc 10:1) to afford 10a as a pale, straw-coloured oil $(25 \mathrm{mg}, 76 \%)$. IR (neat) $v_{\max } 964,1147,1190,1678,1733,2924 \mathrm{~cm}^{-1}$. ${ }^{1} \mathrm{H}-\mathrm{NMR}\left(\mathrm{CDCl}_{3}\right) \delta_{\mathrm{H}} 1.47\left(6 \mathrm{H}, \mathrm{s},\left(\mathrm{CH}_{3}\right)_{2}\right), 2.88\left(2 \mathrm{H}, \mathrm{s}, \mathrm{C}_{2} \mathrm{CO}\right), 3.30(2 \mathrm{H}, \mathrm{d}, J=7.1 \mathrm{~Hz}$, $\left.\mathrm{CH}_{2} \mathrm{COO}\right), 5.12\left(2 \mathrm{H}, \mathrm{s}, \mathrm{OCH}_{2}\right), 6.31(1 \mathrm{H}, \mathrm{m}, \mathrm{CH}=\mathrm{C}), 6.50(1 \mathrm{H}, \mathrm{m}, \mathrm{CH}=\mathrm{C}), 7.21-7.43(7 \mathrm{H}, \mathrm{m}$, $7 \times \mathrm{Ar} \underline{\mathrm{H}}), 8.11(1 \mathrm{H}, \mathrm{d}, J=1.5 \mathrm{~Hz}, \underline{\mathrm{H}} 5) .{ }^{13} \mathrm{C}$ NMR $\delta_{\mathrm{C}} 28.6(2 \underline{\mathrm{C}}), 38.3,44.8,53.7,65.8,121.4$, 
126.3 (2ㄷ) $), 127.6,128.0,128.5,128.6$ (2ㄷ) $), 129.7,132.5,133.6,133.7,136.8,141.7,171.4,194.7$. HRMS $\left(\mathrm{M}+\mathrm{NH}_{4}\right)^{+} 384.1611, \mathrm{C}_{22} \mathrm{H}_{26} \mathrm{NO}_{3} \mathrm{~S}$ requires 384.1628 .

(2,2-Dimethyl-4-oxothiochroman-6-yl)methyl

(2E,4E)-5-(benzo[d][1,3]dioxol-5-yl)penta-2,4-dienoate (10b)

Compound 18 (25 mg, $0.11 \mathrm{mmol})$ was reacted as for 10a with piperic acid (24 mg, $0.11 \mathrm{mmol}$ ) to afford $\mathbf{1 0 b}$ as a straw-coloured oil $(31 \mathrm{mg}, 65 \%)$. IR (neat) $v_{\max } 994,1035,1126$, 1232, 1250, 1445, 1603, 1677, 1705, $2924 \mathrm{~cm}^{-1} .{ }^{1} \mathrm{H}-\mathrm{NMR}\left(\mathrm{CDCl}_{3}\right) \delta_{\mathrm{H}} 1.47\left(6 \mathrm{H}, \mathrm{s},\left(\mathrm{CH}_{3}\right)_{2}\right)$, $2.88\left(2 \mathrm{H}, \mathrm{s}, \mathrm{CH}_{2} \mathrm{CO}\right), 5.17\left(2 \mathrm{H}, \mathrm{s}, \mathrm{ArCH}_{2} \mathrm{O}\right), 5.98\left(3 \mathrm{H}, \mathrm{m}, \mathrm{OCH}_{2} \mathrm{O} \& \mathrm{CH}=\mathrm{C}\right), 6.70(1 \mathrm{H}, \mathrm{m}$, $\mathrm{C}=\mathrm{CH}), 6.78-6.64(2 \mathrm{H}, \mathrm{m}, 2 \times \mathrm{C}=\mathrm{CH}), 6.91(1 \mathrm{H}, \mathrm{d}, J=8.3 \mathrm{~Hz}, \mathrm{C}=\mathrm{CH}), 6.99(1 \mathrm{H}, \mathrm{s}, \mathrm{C}=\mathrm{CH})$, $7.24(1 \mathrm{H}, \mathrm{d}, J=8.1 \mathrm{~Hz}, \mathrm{C}=\mathrm{C} \underline{\mathrm{H}}), 7.42-7.48(2 \mathrm{H}, \mathrm{m}, 2 \times \mathrm{C}=\mathrm{C} \underline{\mathrm{H}}), 8.13$ (1H, br. s, $\underline{\mathrm{H}} 5) .{ }^{13} \mathrm{C}-\mathrm{NMR}$ $\delta_{\mathrm{C}} 28.6(2 \underline{\mathrm{C}}), 44.8,53.8,65.4,101.4,105.9,108.6,119.7,123.1,124.4,127.9,128.5,129.7,130.5$, 133.0, 133.6, 140.7, 141.5, 145.6, 148.3, 148.7, 166.9, 194.7. HRMS $\left(\mathrm{M}+\mathrm{NH}_{4}\right)^{+} 440.1570$, $\mathrm{C}_{24} \mathrm{H}_{26} \mathrm{NO}_{5} \mathrm{~S}$ requires 440.1526 .

6-(Bromomethyl)-2,2-dimethylthiochroman-4-one (19)

Compound 16 (1.55 g (7.5 mmol) was dissolved in cyclohexane $(25 \mathrm{~mL})$. To this stirred solution was added $N$-bromosuccinimide $(2.66 \mathrm{~g}, 14.9 \mathrm{mmol})$ and a catalytic quantity of dibenzoylperoxide, and the reaction mixture was stirred at $100{ }^{\circ} \mathrm{C}$ for $6 \mathrm{~h}$. Upon completion, the solvent was removed in vacuo, and the residue purified by flash chromatography (pet. ether/EtOAc 10:1) to give 19 as a golden oil (1.072 g, 51\%), which solidified on standing. IR $v_{\max }$ (neat) $1676 \mathrm{~cm}^{-1} ;{ }^{1} \mathrm{H}-\mathrm{NMR}\left(\mathrm{CDCl}_{3}\right) \delta_{\mathrm{H}} 1.47\left(6 \mathrm{H}, \mathrm{s},\left(\mathrm{CH}_{3}\right)_{2}, 2.87(2 \mathrm{H}\right.$, $\left.\mathrm{s}, \underline{\mathrm{CH}}_{2}\right), 4.48\left(2 \mathrm{H}, \mathrm{s}, \mathrm{ArC}_{2}\right), 7.22(1 \mathrm{H}, \mathrm{d}, J=8.2 \mathrm{~Hz}, \underline{\mathrm{H}} 8), 7.45(1 \mathrm{H}, \mathrm{dd}, J=8.2,2.1 \mathrm{~Hz}$, $\underline{\mathrm{H}} 7), 8.10(1 \mathrm{H}, \mathrm{d}, J=2.2 \mathrm{~Hz}, \underline{\mathrm{H}} 5) ;{ }^{13} \mathrm{C}-\mathrm{NMR} \delta_{\mathrm{C}} 28.6\left(\left(\underline{\mathrm{CH}}_{3}\right)_{2}\right), 32.7\left(\underline{\mathrm{CH}_{2}}\right), 44.9\left(\underline{\mathrm{C}}\left(\mathrm{CH}_{3}\right)_{2}\right)$, 53.6 $\left(\underline{\mathrm{CH}}_{2}\right), 128.3(\mathrm{ArCH}), 128.9(\mathrm{ArCH}), 129.7(\mathrm{ArC}), 134.2(\mathrm{ArCH}), 134.4(\mathrm{ArC}), 141.9(\mathrm{ArC})$, $194.5(\underline{C}=\mathrm{O})$.

6-(Azidomethyl)-2,2-dimethylthiochroman-4-one (20)

To a solution of $19(0.81 \mathrm{~g}, 2.84 \mathrm{mmol})$ in DMF $(6 \mathrm{~mL})$ was added sodium azide ( $2 \mathrm{~g}, 30.8 \mathrm{mmol})$. The resultant slurry was heated on an oil bath for $4 \mathrm{~h}$ at $50{ }^{\circ} \mathrm{C}$, and then partitioned between water and ethyl acetate. The aqueous layer was washed twice with ethyl acetate $(2 \times 20 \mathrm{~mL}$ portions $)$ and the combined organic layers dried over sodium sulfate and concentrated in vacuo. The residue was purified by flash column chromatography on silica gel (pet. ether/EtOAc 10:1) to yield the azide $(0.52 \mathrm{~g}, 74 \%)$ as a bright yellow oil. ${ }^{1} \mathrm{H}-\mathrm{NMR}\left(\mathrm{CDCl}_{3}\right) \delta_{\mathrm{H}} 1.48\left(6 \mathrm{H}, \mathrm{s},\left(\mathrm{C}_{3}\right)_{2}, 2.89\left(2 \mathrm{H}, \mathrm{s}, \mathrm{CH}_{2} \mathrm{CO}\right), 4.34(2 \mathrm{H}, \mathrm{s}\right.$, $\left.\mathrm{CH}_{2} \mathrm{~N}_{3}\right), 7.27(1 \mathrm{H}, \mathrm{d}, J=8 \mathrm{~Hz}, \underline{\mathrm{H}} 8), 7.38(1 \mathrm{H}, \mathrm{dd}, J=8,2 \mathrm{~Hz}, \underline{\mathrm{H}} 7), 8.04(1 \mathrm{H}, \mathrm{d}, J=1.7 \mathrm{~Hz}, \underline{\mathrm{H}} 5)$; ${ }^{13} \mathrm{C}-\mathrm{NMR} \delta_{\mathrm{C}} 28.6\left(\left(\underline{\mathrm{CH}}_{3}\right)_{2}\right), 44.8(\underline{\mathrm{C}} 2), 53.7\left(\underline{\mathrm{CH}}_{2}\right), 54.1\left(\underline{\mathrm{CH}}_{2}\right), 128.3(\mathrm{Ar} \underline{\mathrm{CH}}), 128.3(\mathrm{Ar} \underline{\mathrm{CH}})$,

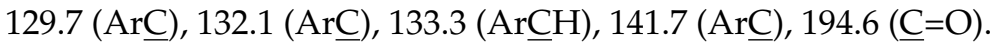

\section{6-(Aminomethyl)-2,2-dimethylthiochroman-4-one (21)}

To 20 (57 mg, $0.23 \mathrm{mmol})$ in EtOH/ $\mathrm{H}_{2} \mathrm{O}(3: 1,5 \mathrm{~mL})$ was added $\mathrm{Zn}(20 \mathrm{mg}, 0.31 \mathrm{mmol})$ and $\mathrm{NH}_{4} \mathrm{Cl}(25 \mathrm{mg}, 0.47 \mathrm{mmol})$. The mixture was stirred vigorously at room temperature for $24 \mathrm{~h}$ followed by reflux for $6 \mathrm{~h}$. Ethyl acetate $(20 \mathrm{~mL})$ and $\mathrm{NaOH}(1 \mathrm{M})(1 \mathrm{~mL})$ were added. The mixture was filtered, and the filtrate was washed with brine, dried over anhydrous sodium sulfate. Removal of solvent under reduced pressure afforded a yellow oil. ${ }^{1} \mathrm{H}-\mathrm{NMR}\left(\mathrm{CDCl}_{3}\right) \delta_{\mathrm{H}} 1.47\left(6 \mathrm{H}, \mathrm{s},\left(\mathrm{CH}_{3}\right)_{2}, 2.88\left(2 \mathrm{H}, \mathrm{s}, \mathrm{CH}_{2} \mathrm{CO}\right), 3.86\left(2 \mathrm{H}, \mathrm{s}, \mathrm{CH}_{2} \mathrm{NH}_{2}\right)\right.$, $7.21(1 \mathrm{H}, \mathrm{d}, J=8.1 \mathrm{~Hz}, \underline{\mathrm{H}} 8), 7.40(1 \mathrm{H}, \mathrm{dd}, J=8.1,1.8 \mathrm{~Hz}, \underline{\mathrm{H}} 7), 8.04(1 \mathrm{H}, \mathrm{d}, J=1.3 \mathrm{~Hz}, \underline{\mathrm{H}} 5)$; ${ }^{13} \mathrm{C}-\mathrm{NMR} \delta_{\mathrm{C}} 28.6\left(\left(\underline{\mathrm{CH}}_{3}\right)_{2}\right), 44.7(\underline{\mathrm{C}} 2), 45.7\left(\underline{\mathrm{CH}}_{2}\right), 53.9\left(\underline{\mathrm{CH}_{2}}\right), 127.0(\mathrm{ArCH}), 127.9(\mathrm{Ar} \underline{\mathrm{CH}})$,

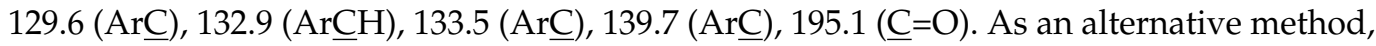
to a mixture of $20(462 \mathrm{mg}, 1.87 \mathrm{mmol})$ in THF $(10 \mathrm{~mL})$ and $\mathrm{H}_{2} \mathrm{O}(1 \mathrm{~mL})$ was added $\mathrm{PPh}_{3}$ $(0.86 \mathrm{~g}, 3.29 \mathrm{mmol})$. The reaction mixture was stirred at RT for $12 \mathrm{~h}$. The mixture was acidified to $\mathrm{pH}=1$ with $1 \mathrm{~N} \mathrm{HCl}$ and extracted with EtOAc $(100 \mathrm{~mL})$. The aqueous layer was separated and the $\mathrm{pH}$ adjusted to $\mathrm{pH} 10$ with $1 \mathrm{~N} \mathrm{NaOH}$, and extracted with DCM $(3 \times 100 \mathrm{~mL})$. The residual solvent was removed in vacuo to afford $302 \mathrm{mg}(73 \%)$ of 21 . 


\section{(E)-N-((2,2-Dimethyl-4-oxothiochroman-6-yl)methyl)-4-phenylbut-3-enamide (11a)}

To a solution of trans-styrylacetic acid (41 mg, $0.25 \mathrm{mmol})$ in dichloromethane $(5 \mathrm{~mL})$ at $0{ }^{\circ} \mathrm{C}$ under a $\mathrm{N}_{2}$ atmosphere was added EDC- $\mathrm{HCl}(100 \mathrm{mg}, 0.52 \mathrm{mmol})$ and triethylamine (0.09 mL, $0.65 \mathrm{mmol})$. After $30 \mathrm{~min}, 21$ (50 mg, $0.23 \mathrm{mmol})$ was added to this solution. The reaction was allowed to reach room temperature and stirred for $24 \mathrm{~h}$. The residual solvent was removed in vacuo, the residue extracted with saturated $\mathrm{NaHCO}_{3} / \mathrm{DCM}$, and the crude organic residue purified by flash column chromatography (pet. ether/EtOAc $5: 1)$ to afford amide 11a as a pale oil $(56 \mathrm{mg}, 67 \%)$. IR (neat) $v_{\max } 965,1186,1212$, 1304, 1468, 1538, 1675, $2923 \mathrm{~cm}^{-1} ;{ }^{1} \mathrm{H}-\mathrm{NMR}\left(\mathrm{CDCl}_{3}\right) \delta_{\mathrm{H}} 1.46\left(6 \mathrm{H}, \mathrm{s},\left(\mathrm{C}_{3}\right)_{2}, 2.86(2 \mathrm{H}\right.$, s, $\left.\mathrm{CH}_{2} \mathrm{CO}\right), 3.22\left(2 \mathrm{H}, \mathrm{d}, J=7.1 \mathrm{~Hz}, \mathrm{CH}_{2} \mathrm{C}=\mathrm{C}\right), 4.43\left(2 \mathrm{H}, \mathrm{d}, J=5.9 \mathrm{~Hz}, \mathrm{CH}_{2} \mathrm{~N}\right), 5.97(1 \mathrm{H}$, br., $\mathrm{NH}), 6.31\left(1 \mathrm{H}, \mathrm{m}, \mathrm{CH}_{2} \mathrm{CH}=\mathrm{CH}\right), 6.55\left(1 \mathrm{H}, \mathrm{m}, \mathrm{CH}_{2} \mathrm{CH}=\mathrm{CH}\right), 7.19-7.39(7 \mathrm{H}, \mathrm{m}, 7 \times \mathrm{ArH})$, $7.98(1 \mathrm{H}, \mathrm{d}, J=1.7 \mathrm{~Hz}, \underline{\mathrm{H}} 5) ;{ }^{13} \mathrm{C}-\mathrm{NMR} \delta_{\mathrm{C}} 28.6\left(\left(\mathrm{CH}_{3}\right)_{2}\right), 40.8\left(\mathrm{CH}_{2}\right), 43.0\left(\underline{\mathrm{CH}}_{2}\right), 44.7(\underline{\mathrm{C}} 2)$, $53.8\left(\underline{\mathrm{CH}}_{2}\right), 122.0,126.4(2 \underline{\mathrm{C}}), 127.6,127.9,128.2,128.7(2 \underline{\mathrm{C}}), 133.4,134.9$ (ArC $), 135.1,140.7$ $(\mathrm{Ar} \underline{\mathrm{C}}), 170.7(\mathrm{NHC}=\mathrm{O}), 194.8(\underline{\mathrm{C}}=\mathrm{O})\left(2 \mathrm{C}\right.$ signals obscured). HRMS $(\mathrm{M}+\mathrm{Na})^{+} 388.1361$, $\mathrm{C}_{22} \mathrm{H}_{23} \mathrm{NO}_{2} \mathrm{NaS}$ requires 388.1347 .

\section{(2,2-Dimethyl-4-oxothiochroman-6-yl)methyl-6-phenylhex-5-enoate (E:Z 3:1) (11b)}

Compound 21 (87 mg (0.39 mmol) was reacted as described for 11a with 6-phenylhex5-enoic acid ( $75 \mathrm{mg}, 0.39 \mathrm{mmol})$ to afford $\mathbf{1 1 b}$ as a pale straw-coloured oil that on standing became a semi-solid gum (113 mg, 73\%). IR (neat) $v_{\max } 964,1091,1213,1304,1466,1648$, $1676,2852,2922,2955 \mathrm{~cm}^{-1} ;{ }^{1} \mathrm{H}-\mathrm{NMR}\left(\mathrm{CDCl}_{3}\right) \delta_{\mathrm{H}} 1.46\left(6 \mathrm{H}, \mathrm{s},\left(\mathrm{CH}_{3}\right)_{2}, 1.82-1.90(2 \mathrm{H}, \mathrm{m}\right.$, $\left.\mathrm{CH}_{2}\right), 2.19-2.40\left(4 \mathrm{H}, \mathrm{m}, \mathrm{NHCOCH}_{2} \& \mathrm{C}=\mathrm{CHCH}_{2}\right), 2.86\left(2 \mathrm{H}, \mathrm{s}, \underline{\mathrm{CH}}_{2} \mathrm{CO}\right), 4.30$ \& $4.41(2 \mathrm{H}$, $\left.2 \times \mathrm{d}, J=5.7 \mathrm{~Hz}, \mathrm{ArCH}_{2} \mathrm{~N}\right), 5.53 \& 5.81(1 \mathrm{H}, \mathrm{br} ., \mathrm{NH}), 6.18(1 \mathrm{H}, \mathrm{m}, \mathrm{C} \underline{\mathrm{H}}=\mathrm{CHAr}), 6.37 \& 6.46$ $(1 \mathrm{H}, 2 \times \mathrm{d}, J=15.9 \& 11.7 \mathrm{~Hz}, \mathrm{CH}=\mathrm{C} \underline{\mathrm{HA}}), 7.15-7.36(7 \mathrm{H}, \mathrm{m}, 7 \times \mathrm{Ar} \underline{\mathrm{H}}), 7.93 \& 7.97(1 \mathrm{H}$, $2 \times \mathrm{s}, \underline{\mathrm{H}} 5) ;{ }^{13} \mathrm{C}-\mathrm{NMR} \delta_{\mathrm{C}} 25.1\left(\underline{\mathrm{CH}}_{2}\right), 28.6\left(\left(\mathrm{CH}_{3}\right)_{2}\right), 32.4\left(\underline{\mathrm{CH}}_{2}\right), 35.9\left(\mathrm{CH}_{2}\right), 42.9\left(\underline{\mathrm{CH}}_{2}\right), 44.7$ (드), $53.8\left(\underline{\mathrm{CH}}_{2}\right), 126.0(2 \underline{\mathrm{C}}), 127.0,127.5,128.1,128.2,128.5$ (2ㄷ) $), 129.7,130.8,133.4,135.2$ $(\mathrm{Ar} \underline{\mathrm{C}}), 137.5(\mathrm{Ar} \underline{\mathrm{C}}), 140.6(\mathrm{Ar} \underline{\mathrm{C}}), 172.7(\mathrm{NH} \underline{\mathrm{C}}=\mathrm{O}), 194.8(\underline{\mathrm{C}}=\mathrm{O})$, (signals for $E$ isomer reported, 1 quaternary signal obscured); HRMS $(\mathrm{M}+\mathrm{Na})^{+} 416.1645, \mathrm{C}_{24} \mathrm{H}_{27} \mathrm{NO}_{2} \mathrm{NaS}$ requires 416.1660 .

(2E,4E)-5-(Benzo[d][1,3]dioxol-5-yl)-N-((2,2-dimethyl-4-oxothiochroman-6-yl)methyl)penta-2,4dienamide (11c)

Compound 21 (80 mg, $0.36 \mathrm{mmol})$ was reacted as for 11a with piperic acid (79 $\mathrm{mg}$, $0.36 \mathrm{mmol}$ ) to afford 11c as a pale yellow solid $(63 \mathrm{mg}, 41 \%)$. IR (neat) $v_{\max } 982,1036,1190$, 1250, 1443, 1536, 1614, 1644, 1679, $3278 \mathrm{~cm}^{-1},{ }^{1} \mathrm{H}-\mathrm{NMR}\left(\mathrm{CDCl}_{3^{-}}\right) \delta_{\mathrm{H}} 1.45\left(6 \mathrm{H}, \mathrm{s},\left(\mathrm{CH}_{3}\right)_{2}\right.$, $2.85\left(2 \mathrm{H}, \mathrm{s}, \mathrm{CH}_{2}\right), 4.51\left(2 \mathrm{H}, \mathrm{d}, J=5.9 \mathrm{~Hz}, \underline{\mathrm{CH}}_{2} \mathrm{~N}\right), 5.94(1 \mathrm{H}, \mathrm{d}, J=14.9 \mathrm{~Hz}, \mathrm{COC} \underline{\mathrm{H}}=\mathrm{C})$, $5.98\left(2 \mathrm{H}, \mathrm{s}, \mathrm{OC} \underline{\mathrm{H}}_{2} \mathrm{O}\right), 6.04(1 \mathrm{H}$, br. $\mathrm{t}, \mathrm{NH}), 6.65 \& 6.68(1 \mathrm{H}, 2 \times \mathrm{d}, J=10.6 \mathrm{~Hz}, \mathrm{C} \underline{\mathrm{H}}=\mathrm{CH})$, $6.78(2 \mathrm{H}, \mathrm{m}, 2 \times \mathrm{CH}=\mathrm{C}), 6.89(1 \mathrm{H}, \mathrm{d}, J=8.1 \mathrm{~Hz}, \mathrm{C} \underline{\mathrm{H}}=\mathrm{C}), 6.97(1 \mathrm{H}, \mathrm{br} . \mathrm{s}, \mathrm{C} \underline{\mathrm{H}}=\mathrm{C}), 7.20$ $(1 \mathrm{H}, \mathrm{d}, J=8.1 \mathrm{~Hz}, \overline{\mathrm{CH}}=\mathrm{C}), 7.39(2 \mathrm{H}, \mathrm{m}, 2 \times \mathrm{CH}=\mathrm{C}), 8.00(1 \mathrm{H}$, br. $\mathrm{s}, \mathrm{CH}=\mathrm{C}) ;{ }^{13} \mathrm{C}-\mathrm{NMR}$ $\delta_{\mathrm{C}} 28.6\left(\left(\underline{\mathrm{CH}}_{3}\right)_{2}\right), 43.0\left(\underline{\mathrm{C}} \mathrm{H}_{2}\right), 44.7\left(\underline{\mathrm{C}}\left(\mathrm{CH}_{3}\right)_{2}\right), 53.8\left(\underline{\mathrm{CH}}_{2}\right), 101.3\left(\mathrm{O}_{\underline{C}}{ }_{2} \mathrm{O}\right), 105.8(\underline{\mathrm{CH}}=\mathrm{C})$, $108.5(\underline{\mathrm{CH}}=\mathrm{C}), 122.5(\underline{\mathrm{CH}}=\mathrm{C}), 122.8(\underline{\mathrm{CH}}=\mathrm{C}), 124.5(\underline{\mathrm{C}}=\mathrm{C}), 127.5(\underline{\mathrm{C}} \mathrm{H}=\mathrm{C}), 128.1(\underline{\mathrm{CH}}=\mathrm{C})$, 129.6 (ArC), 130.8 (ArC), 133.5 ( $\underline{\mathrm{CH}}=\mathrm{C}), 135.2$ (ArC), 139.4 ( $\underline{\mathrm{CH}}=\mathrm{C}), 140.6$ (ArC), 141.8

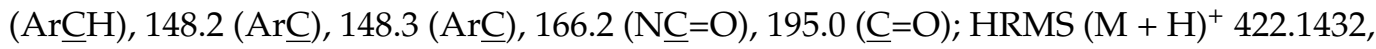
$\mathrm{C}_{24} \mathrm{H}_{24} \mathrm{NO}_{4} \mathrm{~S}$ requires 422.1426 .

\section{N-((2,2-Dimethyl-4-oxothiochroman-6-yl)methyl)octanamide (11d)}

Compound 21 (87 mg, $0.39 \mathrm{mmol})$ was reacted as for 11a with octanoic acid (56 mg, $0.39 \mathrm{mmol}$ ) to afford $\mathbf{1 1 d}$ as a pale straw-coloured oil that on standing became a semi-solid gum $(102 \mathrm{mg}, 75 \%)$. IR (neat) $v_{\max } 1193,1306,1407,1462,1530,1639,1680,2852,2923$, $3297 \mathrm{~cm}^{-1},{ }^{1} \mathrm{H}-\mathrm{NMR}\left(\mathrm{CDCl}_{3}, 400 \mathrm{MHz}\right) \delta_{\mathrm{H}} 0.87\left(3 \mathrm{H}, \mathrm{t}, \mathrm{CH}_{2} \mathrm{CH}_{3}\right), 1.28\left(\mathrm{~m}, 8 \mathrm{H}, 4 \times \mathrm{CH}_{2}\right)$, $1.46\left(6 \mathrm{H},\left(\mathrm{CH}_{3}\right)_{2}\right), 1.65\left(2 \mathrm{H}, \mathrm{m}, \mathrm{CH}_{2}\right), 2.22\left(2 \mathrm{H}, \mathrm{m}, \mathrm{CH}_{2} \mathrm{CONH}\right), 2.86\left(2 \mathrm{H}, \mathrm{s}, \mathrm{CH}_{2} \mathrm{CO}\right), 4.41$ $\left(2 \mathrm{H}, \mathrm{d}, J=5.9 \mathrm{~Hz}, \mathrm{CH}_{2} \mathrm{~N}\right), 5.86(1 \mathrm{H}, \mathrm{br} ., \mathrm{NH}), 7.20(1 \mathrm{H}, \mathrm{d}, J=8.1 \mathrm{~Hz}, \underline{\mathrm{H}} 8), 7.36(1 \mathrm{H}, \mathrm{dd}, J=8.1$, $2.0 \mathrm{~Hz}, \underline{\mathrm{H}} 7), 7.97(1 \mathrm{H}, J=1.5 \mathrm{~Hz}, \underline{\mathrm{H}} 5) ;{ }^{13} \mathrm{C}-\mathrm{NMR} \delta_{\mathrm{C}} 14.1\left(\underline{\mathrm{CH}}_{3}\right), 22.6\left(\mathrm{CH}_{2}\right), 25.7\left(\underline{\mathrm{CH}}_{2}\right), 28.6$ $\left(\left(\underline{\mathrm{CH}}_{3}\right)_{2}\right), 29.0\left(\underline{\mathrm{CH}}_{2}\right), 29.3\left(\underline{\mathrm{CH}}_{2}\right), 31.7\left(\underline{\mathrm{CH}}_{2}\right), 36.8\left(\underline{\mathrm{CH}}_{2}\right), 42.8\left(\underline{\mathrm{CH}}_{2}\right), 44.7\left(\underline{\mathrm{C}}\left(\mathrm{CH}_{3}\right)_{2}\right), 53.8$ 


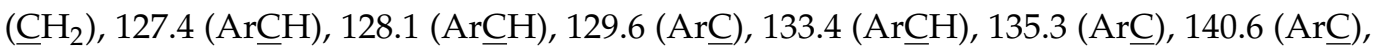
$173.2(\mathrm{NC}=\mathrm{O}), 194.9(\underline{\mathrm{C}}=\mathrm{O})$; HRMS $(\mathrm{M}+\mathrm{Na})^{+} 370.1831, \mathrm{C}_{20} \mathrm{H}_{29} \mathrm{NO}_{2} \mathrm{NaS}$ requires 370.1817.

\section{9-Bromo-N-((2,2-dimethyl-4-oxothiochroman-6-yl)methyl)nonanamide (11e)}

Compound 21 (100 mg, $0.45 \mathrm{mmol}$ ) was reacted as for 11a with 9-bromononanoic acid (100 mg, $0.42 \mathrm{mmol}$ ) to afford 11e as a pale straw-coloured oil that on standing became a semi-solid gum $(123 \mathrm{mg}, 62 \%)$. IR (neat) $v_{\max } 1215,1300,1463,1539,1647,1675,2855$, $2924 \mathrm{~cm}^{-1} ;{ }^{1} \mathrm{H}-\mathrm{NMR}\left(\mathrm{CDCl}_{3}\right) \delta_{\mathrm{H}} 1.25-1.86\left(\mathrm{~m}, 12 \mathrm{H}, 6 \times \mathrm{CH}_{2}\right), 1.46\left(6 \mathrm{H}, \mathrm{s},\left(\mathrm{CH}_{3}\right)_{2}, 2.22(2 \mathrm{H}\right.$, $\left.\mathrm{m}, \mathrm{NHCOC} \underline{\mathrm{H}}_{2}\right), 2.86\left(2 \mathrm{H}, \mathrm{s}, \mathrm{CH}_{2} \mathrm{CO}\right), 3.41\left(2 \mathrm{H}, \mathrm{m}, \mathrm{C}_{2} \mathrm{Br}\right), 4.42\left(2 \mathrm{H}, \mathrm{d}, J=5.9 \mathrm{~Hz}, \mathrm{C}_{2} \mathrm{~N}\right)$, $5.82(1 \mathrm{H}$, br., $\mathrm{NH}), 7.21(1 \mathrm{H}, \mathrm{d}, J=8.2 \mathrm{~Hz}, \underline{\mathrm{H}} 8), 7.36(1 \mathrm{H}, \mathrm{dd}, J=8.2,2.2 \mathrm{~Hz}, \underline{\mathrm{H}} 7), 7.97(1 \mathrm{H}, \mathrm{dd}$, $J=2,0.2 \mathrm{~Hz}, \underline{\mathrm{H}} 5) ;{ }^{13} \mathrm{C}-\mathrm{NMR} \delta_{\mathrm{C}} 25.6\left(\mathrm{CH}_{2}\right), 28.1\left(\mathrm{CH}_{2}\right), 28.5\left(\underline{\mathrm{CH}}_{2}\right), 28.6\left(\left(\underline{\mathrm{CH}}_{3}\right)_{2}\right), 29.1\left(\underline{\mathrm{CH}}_{2}\right)$, $29.2\left(\mathrm{CH}_{2}\right), 32.8\left(\mathrm{CH}_{2}\right), 34.0\left(\mathrm{CH}_{2}\right), 36.7\left(\mathrm{CH}_{2}\right), 42.8\left(\mathrm{CH}_{2}\right), 44.7\left(\underline{\mathrm{C}}\left(\mathrm{CH}_{3}\right)_{2}\right), 53.8\left(\mathrm{CH}_{2}\right), 127.4$ $(\mathrm{Ar} \underline{\mathrm{CH}}), 128.1(\mathrm{Ar} \underline{\mathrm{C}} \mathrm{H}), 129.7(\mathrm{Ar} \underline{\mathrm{C}}), 133.4(\mathrm{Ar} \underline{\mathrm{CH}}), 135.3(\mathrm{Ar} \underline{\mathrm{C}}), 140.6(\mathrm{Ar} \underline{\mathrm{C}}), 173.0(\mathrm{~N} \underline{\mathrm{C}}=\mathrm{O})$, $194.9(\mathrm{C}=\mathrm{O})$; $\mathrm{HRMS}(\mathrm{M}+\mathrm{Na})^{+} 462.1078, \mathrm{C}_{21} \mathrm{H}_{30} \mathrm{NO}_{2} \mathrm{NaSBr}$ requires 462.1078 .

\section{6-((Butylamino)methyl)-2,2-dimethylthiochroman-4-one (12a)}

Compound 19 (100 mg, $0.35 \mathrm{mmol})$ was dissolved in acetonitrile $(25 \mathrm{~mL})$ under aerobic conditions. To this stirred solution was added excess $n$-butylamine, and the reaction mixture was stirred at $100{ }^{\circ} \mathrm{C}$ for $2 \mathrm{~h}$. Upon completion, the solvent was removed in vacuo, and the residue purified by flash chromatography (pet. ether/EtOAc 2:1) to give 12a as a pale brown oil (74 $\mathrm{mg}, 76 \%$ ), without contamination with any tertiary amine. IR $v_{\max }$ (neat) $1249,1464,1601,1679 \mathrm{~cm}^{-1} ;{ }^{1} \mathrm{H}-\mathrm{NMR}\left(\mathrm{CDCl}_{3}\right) \delta_{\mathrm{H}} 0.91\left(3 \mathrm{H}, \mathrm{t}, J=7.3 \mathrm{~Hz}, \mathrm{CH}_{3}\right), 1.34(2 \mathrm{H}, \mathrm{m}$, $\left(\mathrm{CH}_{2}\right), 1.46\left(6 \mathrm{H}, \mathrm{s},\left(\mathrm{CH}_{3}\right)_{2}, 1.48\left(2 \mathrm{H}, \mathrm{m}, \mathrm{CH}_{2}\right), 2.61\left(2 \mathrm{H}, \mathrm{t}, J=7.2 \mathrm{~Hz},\left(\mathrm{NC}_{2} \mathrm{CH}_{2}\right), 2.87(2 \mathrm{H}\right.\right.$, $\left.\mathrm{s}, \mathrm{CH}_{2}\right), 3.76\left(2 \mathrm{H}, \mathrm{s}, \mathrm{ArCH}_{2}\right), 7.20(1 \mathrm{H}, \mathrm{d}, J=8.1 \mathrm{~Hz}, \underline{\mathrm{H}} 8), 7.42(1 \mathrm{H}, \mathrm{dd}, J=8.1,1.6 \mathrm{~Hz}, \underline{\mathrm{H}} 7)$, $8.03(1 \mathrm{H}$, br. d, $\underline{\mathrm{H}} 5) ;{ }^{13} \mathrm{C}-\mathrm{NMR} \delta_{\mathrm{C}} 14.0\left(\underline{\mathrm{CH}}_{3}\right), 20.5\left(\underline{\mathrm{C}} \mathrm{H}_{2}\right), 28.6\left(\left(\underline{\mathrm{CH}}_{3}\right)_{2}\right), 32.2\left(\underline{\mathrm{C}} \mathrm{H}_{2}\right), 44.6$ $\left(\underline{\mathrm{C}}\left(\mathrm{CH}_{3}\right)_{2}\right), 49.1\left(\mathrm{CH}_{2}\right), 53.3\left(\mathrm{CH}_{2}\right), 53.9\left(\underline{\mathrm{CH}}_{2}\right), 127.8(\mathrm{ArCH}), 128.1(\mathrm{Ar} \underline{\mathrm{CH}}), 129.5(\mathrm{ArC})$,

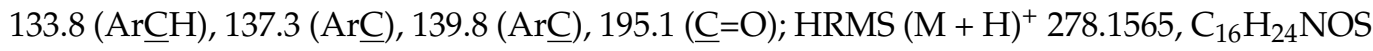
requires 278.1579 .

\section{6-((Hexylamino)methyl)-2,2-dimethylthiochroman-4-one (12b)}

Compound 19 (100 $\mathrm{mg}, 0.35 \mathrm{mmol})$ was reacted as for $12 \mathrm{a}$ with $n$-hexylamine to afford $12 \mathbf{b}$ as a pale brown oil $(82 \mathrm{mg}, 77 \%)$. IR $v_{\max }$ (neat) 1251, 1454, 1528, 1683, $3336 \mathrm{~cm}^{-1} ;{ }^{1} \mathrm{H}-\mathrm{NMR}\left(\mathrm{CDCl}_{3}\right) \delta_{\mathrm{H}} 0.88\left(3 \mathrm{H}, \mathrm{t}, J=6.7 \mathrm{~Hz}, \mathrm{CH}_{3}\right), 1.28\left(6 \mathrm{H}, \mathrm{m},\left(\mathrm{C}_{2}\right)_{3}\right)$, $1.46\left(6 \mathrm{H}, \mathrm{s},\left(\mathrm{CH}_{3}\right)_{2}, 1.48\left(2 \mathrm{H}, \mathrm{m}, \mathrm{CH}_{2}\right), 2.60\left(2 \mathrm{H}, \mathrm{t}, J=7.3 \mathrm{~Hz},\left(\mathrm{NCH}_{2} \mathrm{CH}_{2}\right), 2.87\left(2 \mathrm{H}, \mathrm{s}, \mathrm{CH}_{2}\right)\right.\right.$, $3.76\left(2 \mathrm{H}, \mathrm{s}, \mathrm{ArC}_{2}\right), 7.20(1 \mathrm{H}, \mathrm{d}, J=8.2 \mathrm{~Hz}, \underline{\mathrm{H}} 8), 7.42(1 \mathrm{H}, \mathrm{dd}, J=8.1,2.1 \mathrm{~Hz}, \underline{\mathrm{H}} 7), 8.02$ $(1 \mathrm{H}, \mathrm{d}, J=1.3 \mathrm{~Hz}, \underline{\mathrm{H}} 5) ;{ }^{13} \mathrm{C}-\mathrm{NMR} \delta_{\mathrm{C}} 14.1\left(\mathrm{CH}_{3}\right), 22.6\left(\mathrm{CH}_{2}\right), 27.0\left(\mathrm{CH}_{2}\right), 28.6\left(\left(\mathrm{CH}_{3}\right)_{2}\right), 30.0$ $\left(\underline{\mathrm{CH}}_{2}\right), 31.8\left(\underline{\mathrm{CH}}_{2}\right), 44.6\left(\underline{\mathrm{C}}\left(\mathrm{CH}_{3}\right)_{2}\right), 49.5\left(\underline{\mathrm{CH}}_{2}\right), 53.3\left(\underline{\mathrm{CH}}_{2}\right), 53.9\left(\underline{\mathrm{CH}}_{2}\right), 127.7(\mathrm{Ar} \underline{\mathrm{CH}}), 128.1$ $(\mathrm{Ar} \underline{\mathrm{CH}}), 129.5(\mathrm{Ar} \underline{\mathrm{C}}), 133.8(\mathrm{Ar} \underline{\mathrm{C}} \mathrm{H}), 137.3(\mathrm{Ar} \underline{\mathrm{C}}), 139.8(\mathrm{Ar} \underline{\mathrm{C}}), 195.1(\underline{\mathrm{C}}=\mathrm{O})$; HRMS $(\mathrm{M}+\mathrm{H})^{+}$ 306.1899, $\mathrm{C}_{18} \mathrm{H}_{28} \mathrm{NOS}$ requires 306.1892 .

\section{2,2-Dimethyl-6-((octylamino)methyl)thiochroman-4-one (12c)}

Compound 19 (100 mg, $0.35 \mathrm{mmol})$ was reacted as for 12a with n-octylamine ( $45 \mathrm{mg}$, $0.35 \mathrm{mmol}$ ) to afford $12 \mathrm{c}$ as a pale brown oil ( $98 \mathrm{mg}, 84 \%$ ). IR $v_{\max }$ (neat) $1303,1465,1600$, $1678,2922 \mathrm{~cm}^{-1} ;{ }^{1} \mathrm{H}-\mathrm{NMR}\left(\mathrm{CDCl}_{3}\right) \delta_{\mathrm{H}} 0.87\left(3 \mathrm{H}, \mathrm{t}, J=6.8 \mathrm{~Hz}, \mathrm{CH}_{3}\right), 1.22-1.32(10 \mathrm{H}, \mathrm{m}$, $\left.\left(\mathrm{CH}_{2}\right)_{5}\right), 1.46\left(6 \mathrm{H}, \mathrm{s},\left(\mathrm{CH}_{3}\right)_{2}, 1.48\left(2 \mathrm{H}, \mathrm{m}, \mathrm{CH}_{2}\right), 2.60\left(2 \mathrm{H}, \mathrm{t}, J=7.2 \mathrm{~Hz},\left(\mathrm{NC}_{2} \mathrm{CH}_{2}\right), 2.87(2 \mathrm{H}\right.\right.$, $\left.\mathrm{s}, \mathrm{CH}_{2}\right), 3.76\left(2 \mathrm{H}, \mathrm{s}, \mathrm{ArCH}_{2}\right), 7.20(1 \mathrm{H}, \mathrm{d}, J=8.2 \mathrm{~Hz}, \underline{\mathrm{H}} 8), 7.42(1 \mathrm{H}, \mathrm{dd}, J=8.1,1.8 \mathrm{~Hz}, \underline{\mathrm{H}} 7)$, $8.02(1 \mathrm{H}, \mathrm{d}, J=1.5 \mathrm{~Hz}, \underline{\mathrm{H}} 5) ;{ }^{13} \mathrm{C}-\mathrm{NMR} \delta_{\mathrm{C}} 14.1\left(\underline{\mathrm{CH}}_{3}\right), 22.7\left(\underline{\mathrm{CH}}_{2}\right), 27.4\left(\underline{\mathrm{CH}}_{2}\right), 28.6\left(\left(\underline{\mathrm{CH}}_{3}\right)_{2}\right)$, $29.3\left(\mathrm{CH}_{2}\right), 29.5\left(\mathrm{CH}_{2}\right), 30.1\left(\mathrm{CH}_{2}\right), 31.8\left(\mathrm{CH}_{2}\right), 44.6\left(\underline{\mathrm{C}}\left(\mathrm{CH}_{3}\right)_{2}\right), 49.5\left(\mathrm{CH}_{2}\right), 53.3\left(\mathrm{CH}_{2}\right), 53.9$ $\left(\underline{\mathrm{C}}_{2}\right), 127.8(\mathrm{Ar} \underline{\mathrm{C}} \mathrm{H}), 128.1(\mathrm{Ar} \underline{\mathrm{C}} \mathrm{H}), 129.5(\mathrm{ArC}), 133.8(\mathrm{Ar} \underline{\mathrm{C}} \mathrm{H}), 137.3(\mathrm{Ar} \underline{\mathrm{C}}), 139.8$ (Ar $\left.\underline{\mathrm{C}}\right)$, $195.1(\mathrm{C}=\mathrm{O})$; HRMS $(\mathrm{M}+\mathrm{H})^{+} 334.2195, \mathrm{C}_{20} \mathrm{H}_{32} \mathrm{NOS}$ requires 334.2205.

\section{2,2-Dimethyl-6-((decylamino)methyl)thiochroman-4-one (12d)}

Compound 19 (100 mg, $0.35 \mathrm{mmol})$ was reacted as for 12a with $n$-decylamine ( $55 \mathrm{mg}$, $0.35 \mathrm{mmol}$ ) to afford $\mathbf{1 2} \mathbf{d}$ as a pale golden oil $(100 \mathrm{mg}, 79 \%)$. IR $v_{\max }$ (neat) 1189,1301 , 
1387, 1468, 1510, 1675, 2852, $2922 \mathrm{~cm}^{-1} ;{ }^{1} \mathrm{H}-\mathrm{NMR}\left(\mathrm{CDCl}_{3^{-}}\right) \delta_{\mathrm{H}} 0.88\left(3 \mathrm{H}, \mathrm{t}, J=6.8 \mathrm{~Hz}, \mathrm{CH}_{3}\right)$, 1.20-1.33 (14H, m, $\left.\left(\mathrm{CH}_{2}\right)_{7}\right), 1.47\left(6 \mathrm{H}, \mathrm{s},\left(\mathrm{CH}_{3}\right)_{2}, 1.49\left(2 \mathrm{H}, \mathrm{m}, \mathrm{CH}_{2}\right), 2.61(2 \mathrm{H}, \mathrm{t}, J=7.2 \mathrm{~Hz}\right.$, $\left(\mathrm{NCH}_{2} \mathrm{CH}_{2}\right), 2.87\left(2 \mathrm{H}, \mathrm{s}, \mathrm{CH}_{2}\right), 3.77\left(2 \mathrm{H}, \mathrm{s}, \mathrm{ArCH}_{2}\right), 7.20(1 \mathrm{H}, \mathrm{d}, J=8.1 \mathrm{~Hz}, \underline{\mathrm{H}} 8), 7.43(1 \mathrm{H}$, $\mathrm{dd}, J=8.2,1.6 \mathrm{~Hz}, \underline{\mathrm{H}} 7), 8.02(1 \mathrm{H}, \mathrm{d}, J=1.2 \mathrm{~Hz}, \underline{\mathrm{H}} 5) ;{ }^{13} \mathrm{C}-\mathrm{NMR} \delta_{\mathrm{C}} 14.2\left(\underline{\mathrm{CH}}_{3}\right), 22.7\left(\mathrm{CH}_{2}\right)$, $27.3\left(\underline{\mathrm{CH}}_{2}\right), 28.6\left(\left(\underline{\mathrm{CH}}_{3}\right)_{2}\right), 29.3\left(\underline{\mathrm{CH}}_{2}\right), 29.57\left(\underline{\mathrm{CH}}_{2}\right), 29.59\left(\underline{\mathrm{CH}}_{2}\right), 29.62\left(\underline{\mathrm{CH}}_{2}\right), 30.0\left(\underline{\mathrm{CH}}_{2}\right)$, $31.9\left(\underline{\mathrm{CH}}_{2}\right), 44.7\left(\underline{\mathrm{C}}\left(\mathrm{CH}_{3}\right)_{2}\right), 49.4\left(\underline{\mathrm{CH}}_{2}\right), 53.2\left(\underline{\mathrm{CH}}_{2}\right), 53.9\left(\underline{\mathrm{CH}}_{2}\right), 127.8(\mathrm{ArCH}), 128.2(\mathrm{ArCH})$,

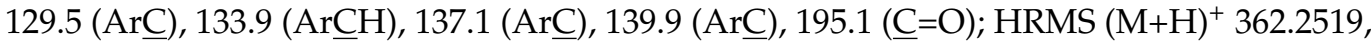
$\mathrm{C}_{22} \mathrm{H}_{36} \mathrm{NOS}$ requires 362.2518 .

6-((Butylimino)methyl)-2,2-dimethylthiochroman-4-one (22a)

To a solution of $17(100 \mathrm{mg}, 0.45 \mathrm{mmol})$ in tetrahydrofuran $(10 \mathrm{~mL})$ was added $n$-butylamine ( $33 \mathrm{mg}, 0.45 \mathrm{mmol}$ ) and sodium triacetoxyborohydride (144 mg, $0.68 \mathrm{mmol})$. To the stirred suspension was added acetic acid $(20 \mu \mathrm{L}, 0.35 \mathrm{mmol})$. The reaction was stirred under a $\mathrm{N}_{2}$ atmosphere at room temperature overnight. The reaction mixture was quenched by adding aqueous saturated $\mathrm{NaHCO}_{3}$, and the product was extracted with EtOAc $(3 \times 30 \mathrm{~mL})$. The EtOAc extract was dried $\left(\mathrm{Na}_{2} \mathrm{SO}_{4}\right)$, and the solvent was evaporated to give the crude imine as a clear oil $(84 \mathrm{mg}, 67 \%) .{ }^{1} \mathrm{H}-\mathrm{NMR}\left(\mathrm{CDCl}_{3^{-}}\right) \delta_{\mathrm{H}}$ $0.86\left(3 \mathrm{H}, \mathrm{t}, J=7.4 \mathrm{~Hz}, \mathrm{CH}_{2} \mathrm{CH}_{3}\right), 1.29\left(2 \mathrm{H}, \mathrm{m}, \mathrm{CH}_{2}\right), 1.40\left(6 \mathrm{H}, \mathrm{s}, \mathrm{C}\left(\mathrm{C}_{3}\right)_{2}\right), 1.58(2 \mathrm{H}, \mathrm{m}$, $\left.\mathrm{CH}_{2}\right), 2.81\left(2 \mathrm{H}, \mathrm{s}, \underline{\mathrm{CH}}_{2}\right), 3.53\left(2 \mathrm{H}, \mathrm{t}, J=7 \mathrm{~Hz}, \mathrm{NCH}_{2}\right), 7.19(1 \mathrm{H}, \mathrm{d}, J=8.3 \mathrm{~Hz}, \underline{\mathrm{H}} 8), 7.84(1 \mathrm{H}$, $\mathrm{dd}, J=8.3,1.4 \mathrm{~Hz}, \underline{\mathrm{H}} 7), 8.18(2 \mathrm{H}, \mathrm{m}, \underline{\mathrm{H}} 5 \mathrm{\&} \mathrm{C} \underline{\mathrm{H}}=\mathrm{N}) .{ }^{13} \mathrm{C}-\mathrm{NMR} \delta_{\mathrm{C}} 13.9\left(\underline{\mathrm{CH}}_{3}\right), 20.4\left(\underline{\mathrm{CH}_{2}}\right), 28.6$ $\left(\left(\mathrm{CH}_{3}\right)_{2}\right), 32.9\left(\underline{\mathrm{CH}}_{2}\right), 44.9\left(\underline{\mathrm{C}}\left(\mathrm{CH}_{3}\right)_{2}\right), 53.6\left(\underline{\mathrm{CH}}_{2}\right), 61.3\left(\underline{\mathrm{CH}}_{2}\right), 128.0(\mathrm{ArCH}), 129.3(\mathrm{ArCH})$,

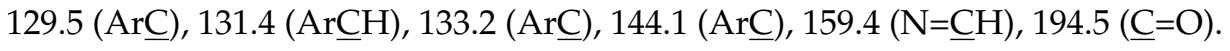

6-((Hexylimino)methyl)-2,2-dimethylthiochroman-4-one (22b)

Compound 17 (98 $\mathrm{mg}, 0.44 \mathrm{mmol}$ ) was reacted as described for 22a with $n$-hexylamine (45 mg, $0.44 \mathrm{mmol})$ to afford $22 \mathrm{~b}$ as a clear oil $(92 \mathrm{mg}, 68 \%) .{ }^{1} \mathrm{H}-\mathrm{NMR}\left(\mathrm{CDCl}_{3}\right) \delta_{\mathrm{H}} 0.81$ $\left(3 \mathrm{H}, \mathrm{t}, \mathrm{CH}_{2} \mathrm{CH}_{3}\right), 1.23-1.29\left(6 \mathrm{H}, \mathrm{m},\left(\mathrm{CH}_{2}\right)_{3}\right), 1.41\left(6 \mathrm{H}, \mathrm{s}, \mathrm{C}\left(\mathrm{CH}_{3}\right)_{2}\right), 1.61\left(2 \mathrm{H}, \mathrm{m}, \mathrm{CH}_{2}\right), 2.82$ $\left(2 \mathrm{H}, \mathrm{s}, \mathrm{CH}_{2}\right), 3.52\left(2 \mathrm{H}, \mathrm{t}, J=7 \mathrm{~Hz}, \mathrm{NC}_{\underline{H_{2}}}\right), 7.20(1 \mathrm{H}, \mathrm{d}, J=8.3 \mathrm{~Hz}, \underline{\mathrm{H}} 8), 7.85(1 \mathrm{H}, \mathrm{dd}, J=8.3$, $2.1 \mathrm{~Hz}, \underline{\mathrm{H}} 7), 8.20(2 \mathrm{H}, \mathrm{m}, \underline{\mathrm{H}} 5 \& \mathrm{C} \underline{\mathrm{H}}=\mathrm{N}) .{ }^{13} \mathrm{C}-\mathrm{NMR} \delta_{\mathrm{C}} 13.1\left(\underline{\mathrm{CH}}_{3}\right), 21.6\left(\underline{\mathrm{CH}}_{2}\right), 26.0\left(\underline{\mathrm{CH}}_{2}\right), 27.6$ $\left(\left(\underline{\mathrm{CH}}_{3}\right)_{2}\right), 29.8\left(\underline{\mathrm{CH}}_{2}\right), 30.6\left(\underline{\mathrm{CH}}_{2}\right), 43.9\left(\underline{\mathrm{C}}\left(\mathrm{CH}_{3}\right)_{2}\right), 52.6\left(\underline{\mathrm{CH}}_{2}\right), 60.7\left(\underline{\mathrm{CH}}_{2}\right), 126.8(\mathrm{Ar} \underline{\mathrm{CH}}), 128.3$

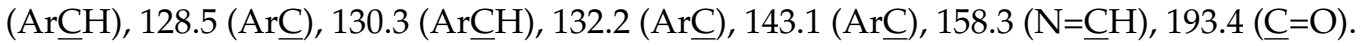

\section{6-((Decylimino)methyl)-2,2-dimethylthiochroman-4-one (22d)}

Compound 17 (87 mg, $0.39 \mathrm{mmol})$ was reacted as for 22a with $n$-decylamine (62 mg, $0.39 \mathrm{mmol})$ to afford $22 \mathrm{~d}$ as a yellow oil $(52 \mathrm{mg}, 37 \%) .{ }^{1} \mathrm{H}-\mathrm{NMR}\left(\mathrm{CDCl}_{3}\right) \delta_{\mathrm{H}} 0.78(3 \mathrm{H}, \mathrm{t}$, $\left.\mathrm{CH}_{2} \mathrm{CH}_{3}\right), 1.20\left(10 \mathrm{H}, \mathrm{m}, 5 \times \mathrm{CH}_{2}\right), 1.38\left(6 \mathrm{H}, \mathrm{s}, \mathrm{C}\left(\mathrm{CH}_{3}\right)_{2}\right), 1.59\left(2 \mathrm{H}, \mathrm{m}, \mathrm{CH}_{2}\right), 2.79(2 \mathrm{H}, \mathrm{s}$, $\left.\mathrm{CH}_{2}\right), 3.50\left(2 \mathrm{H}, \mathrm{t}, J=7 \mathrm{~Hz}, \mathrm{NCH}_{2}\right), 7.16(1 \mathrm{H}, \mathrm{d}, J=8.3, \underline{\mathrm{H}} 8), 7.82(1 \mathrm{H}, \mathrm{d}, J=8.3 \mathrm{~Hz}, \underline{\mathrm{H}} 7)$, $8.16(2 \mathrm{H}, \mathrm{m}, \underline{\mathrm{H}} 5 \mathrm{E} \mathrm{C} \underline{\mathrm{H}}=\mathrm{N}) .{ }^{13} \mathrm{C}-\mathrm{NMR} \delta_{\mathrm{C}} 14.1\left(\underline{\left.\mathrm{CH}_{3}\right)}\right), 22.7,25.6,27.3,28.5\left(\left(\underline{\mathrm{CH}}_{3}\right)_{2}\right), 29.3,29.4$,

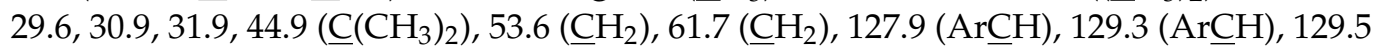
$(\mathrm{ArC}), 131.4(\mathrm{Ar} \underline{\mathrm{CH}}), 133.2(\mathrm{ArC}), 144.0(\mathrm{Ar} \underline{\mathrm{C}}), 159.2(\mathrm{~N}=\underline{\mathrm{CH}}), 194.3(\underline{\mathrm{C}}=\mathrm{O})$.

Reduction of $\mathbf{2 2} \mathbf{a}-\mathbf{d}$ with one equivalent of sodium borohydride in methanol for one hour at $0{ }^{\circ} \mathrm{C}$ to room temperature afforded $12 \mathbf{a}-\mathbf{d}$ in quantitative yield.

\section{2,2,6-Trimethylthiochroman-4-one 1-oxide (23) and 2,2,6-trimethylthiochroman-4-one 1,1-dioxide (24)}

To a suspension of 16 (100 mg, $0.48 \mathrm{mmol})$ in glacial acetic acid (10 mL) was added sodium perborate $4 \mathrm{H}_{2} \mathrm{O}(75 \mathrm{mg}, 0.49 \mathrm{mmol})$, in portions. After stirring at $55^{\circ} \mathrm{C}$ for $4 \mathrm{~h}$, the reaction was poured into ice/water $(100 \mathrm{~mL})$. Ethyl acetate was added and the aqueous layer extracted $(3 \times 50 \mathrm{~mL})$. The organic layers were combined, the solvent removed in vacuo and the residue purified by flash chromatography (pet. ether/EtOAc 8:1) to give two products. 1. Sulfone 24, a clear oil $(69 \mathrm{mg}, 64 \%) ;{ }^{1} \mathrm{H}-\mathrm{NMR}\left(\mathrm{CDCl}_{3}\right) \delta_{\mathrm{H}} 1.53\left(6 \mathrm{H}, \mathrm{s},\left(\mathrm{CH}_{3}\right)_{2}\right.$, $2.49\left(3 \mathrm{H}, \mathrm{s},\left(\mathrm{C}_{3}\right), 3.24\left(2 \mathrm{H}, \mathrm{s}, \mathrm{C}_{2}\right), 7.64(1 \mathrm{H}, \mathrm{d}, J=8.1 \mathrm{~Hz}, \mathrm{Ar} \underline{\mathrm{H}}), 7.91(1 \mathrm{H}, \mathrm{s}, \underline{\mathrm{H}} 5), 7.96(1 \mathrm{H}\right.$, $\mathrm{d}, J=8.1 \mathrm{~Hz}, \overline{\mathrm{Ar}} \underline{\mathrm{H}}) ;{ }^{13} \mathrm{C}-\mathrm{NMR} \delta_{\mathrm{C}} 21.1\left(\left(\underline{\mathrm{CH}}_{3}\right)_{2}\right), 21.6\left(\underline{\mathrm{CH}}{ }_{3}\right), 50.6\left(\underline{\mathrm{CH}}{ }_{2}\right), 58.6\left(\underline{\mathrm{C}}\left(\mathrm{CH}_{3}\right)_{2}\right), 125.0$

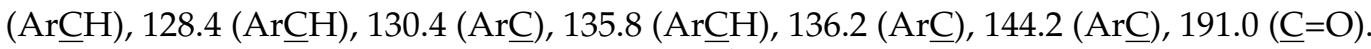
2. Sulfoxide 23 , straw coloured oil $(28 \mathrm{mg}, 24 \%) ;{ }^{1} \mathrm{H}-\mathrm{NMR}\left(\mathrm{CDCl}_{3}\right) \delta_{\mathrm{H}} 1.35 \& 1.41(6 \mathrm{H}, 2 \times \mathrm{s}$, 
$\left(\mathrm{C}_{3}\right)_{2}, 2.47\left(3 \mathrm{H}, \mathrm{s},\left(\mathrm{C}_{3}\right), 2.73\left(1 \mathrm{H}, \mathrm{d}, J=17.5 \mathrm{~Hz}, 1 \mathrm{H}\right.\right.$ of $\left.\mathrm{C}_{2}\right), 3.24(1 \mathrm{H}, \mathrm{d}, J=17.5 \mathrm{~Hz}$, $1 \mathrm{H}$ of $\left.\mathrm{C}_{2}\right), 7.60(1 \mathrm{H}, \bar{d}, J=7.9 \mathrm{~Hz}, \operatorname{Ar} \underline{\mathrm{H}}), 7.78(1 \mathrm{H}, \mathrm{d}, J=8.1 \mathrm{~Hz}, \mathrm{Ar} \underline{\mathrm{H}}), 7.95(1 \mathrm{H}, \mathrm{s}, \underline{\mathrm{H}} 5)$; ${ }^{13} \mathrm{C}-\mathrm{NMR} \delta_{\mathrm{C}} 20.0\left(\underline{\mathrm{CH}}_{3}\right), 21.4\left(\underline{\mathrm{CH}}_{3}\right), 24.0\left(\underline{\mathrm{CH}}_{3}\right), 45.4\left(\underline{\mathrm{CH}}_{2}\right), 56.2\left(\underline{\mathrm{C}}\left(\mathrm{CH}_{3}\right)_{2}\right), 128.7(\mathrm{Ar} \underline{\mathrm{CH}})$, 129.0 (ArC), $129.6(\operatorname{Ar} \underline{\mathrm{CH}}), 135.6(\mathrm{Ar} \underline{\mathrm{CH}}), 140.6(\mathrm{ArC}), 142.4(\mathrm{Ar} \underline{\mathrm{C}}), 192.7(\underline{\mathrm{C}}=\mathrm{O})$.

\section{3-Bromo-2,2,6-trimethylthiochroman-4-one 1,1-dioxide (25)}

Compound 24 (100 mg, $0.45 \mathrm{mmol})$ was dissolved in cyclohexane $/ \mathrm{CH}_{3} \mathrm{CN}(1: 1)$ $(25 \mathrm{~mL})$. To this stirred solution was added $N$-bromosuccinimide $(120 \mathrm{mg}, 0.67 \mathrm{mmol})$ and a catalytic quantity of dibenzoylperoxide, and the reaction mixture was stirred at $100{ }^{\circ} \mathrm{C}$ for $6 \mathrm{~h}$. Upon completion, the solvent was removed in vacuo, and the residue purified by flash chromatography (pet. ether/EtOAc 10:1) to give an orange oil (100 mg, 74\%). ${ }^{1} \mathrm{H}-\mathrm{NMR}\left(\mathrm{CDCl}_{3}\right) \delta_{\mathrm{H}} 1.44 \& 1.75\left(6 \mathrm{H}, 2 \times \mathrm{s},\left(\mathrm{CH}_{3}\right)_{2}, 2.52\left(3 \mathrm{H}, \mathrm{s},\left(\mathrm{CH}_{3}\right), 5.82(1 \mathrm{H}, \mathrm{s}\right.\right.$, $\mathrm{C} \underline{\mathrm{H}}), 7.70(1 \mathrm{H}, \mathrm{d}, J=8.1 \mathrm{~Hz}, \mathrm{Ar} \underline{\mathrm{H}}), 7.95(1 \mathrm{H}, \mathrm{d}, J=7.9 \mathrm{~Hz}, \mathrm{Ar} \underline{\mathrm{H}}), 8.00(1 \mathrm{H}, \mathrm{s}, \underline{\mathrm{H}} 5) ;{ }^{13} \mathrm{C}-\mathrm{NMR}$ $\delta_{\mathrm{C}} 18.8\left(\mathrm{CH}_{3}\right), 20.2\left(\mathrm{CH}_{3}\right), 21.7\left(\underline{\mathrm{CH}}_{3}\right), 62.0(\underline{\mathrm{CH}}), 64.8\left(\underline{\mathrm{C}}\left(\mathrm{CH}_{3}\right)_{2}\right), 125.0(\mathrm{Ar} \underline{\mathrm{CH}}), 127.7(\mathrm{Ar} \underline{\mathrm{C}})$,

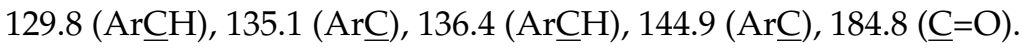

tert-Butyl ((2,2-dimethyl-4-oxothiochroman-6-yl)methyl)(octyl)carbamate (26)

To a solution of $12 \mathrm{c}(200 \mathrm{mg}, 0.60 \mathrm{mmol})$ in DCM $(10 \mathrm{~mL})$ at $0{ }^{\circ} \mathrm{C}$ was added ditert-butyl dicarbonate $(130 \mathrm{mg}, 0.60 \mathrm{mmol})$ and triethylamine $(0.08 \mathrm{~mL}, 0.60 \mathrm{mmol})$. The reaction was stirred overnight, allowing it to reach room temperature. The solvent was evaporated and the residue purified by flash chromatography (pet. ether/EtOAc 8:1) to give 26 as a yellow oil $(150 \mathrm{mg}, 58 \%) .{ }^{1} \mathrm{H}-\mathrm{NMR}\left(\mathrm{CDCl}_{3}, 400 \mathrm{MHz}\right) \delta_{\mathrm{H}} 0.87(3 \mathrm{H}, \mathrm{t}, J=6.6 \mathrm{~Hz}$, $\left.\mathrm{C}_{3}\right), 1.25\left(10 \mathrm{H}, \mathrm{m},\left(\mathrm{C}_{2}\right)_{5}\right), 1.45-1.50\left(17 \mathrm{H}, \mathrm{m}, 5 \times \mathrm{C}_{3}\right.$ and $\left.\underline{\mathrm{C}}_{2}\right), 2.87\left(2 \mathrm{H}, \mathrm{s}, \mathrm{C}_{2} \mathrm{CO}\right)$, $3.16\left(2 \mathrm{H}, \mathrm{m}, \mathrm{NC}_{2} \mathrm{CH}_{2}\right), 4.39\left(2 \mathrm{H}, \mathrm{m}, \mathrm{NCH}_{2} \mathrm{Ar}\right), 7.20(1 \mathrm{H}, \mathrm{dd}, J=8.1,0.4 \mathrm{~Hz}, \mathrm{Ar} \underline{\mathrm{H}}), 7.32$ $(1 \mathrm{H}$, br. d, Ar $\underline{\mathrm{H}}), 7.97$ (1H, br. d, Ar $\underline{\mathrm{H}})$.

\section{2,2-Dimethyl-6-((octylamino)methyl)thiochroman-4-one 1-oxide (13)}

To compound 26 (27 mg, $0.06 \mathrm{mmol})$ in methanol $(1 \mathrm{~mL})$ was added $35 \% \mathrm{H}_{2} \mathrm{O}_{2}(11.3 \mathrm{mg}$ solution, $0.1 \mathrm{mmol})$ and Montmorillonite $\mathrm{K} 10(20 \mathrm{mg})$. The resulting mixture was stirred at room temperature overnight, after which the clay was removed by filtration. The solvent was evaporated to yield BOC-sulfoxide $27 \mathrm{a}(25 \mathrm{mg}, 89 \%) .{ }^{1} \mathrm{H}-\mathrm{NMR}\left(\mathrm{CDCl}_{3},-\right) \delta_{\mathrm{H}} 0.88(3 \mathrm{H}$, $\left.\mathrm{t}, J=6.9 \mathrm{~Hz}, \mathrm{CH}_{3}\right), 1.26\left(10 \mathrm{H}, \mathrm{m},\left(\mathrm{CH}_{2}\right)_{5}\right), 1.41-1.54\left(17 \mathrm{H}, \mathrm{m}, 5 \times \mathrm{CH}_{3}\right.$ and $\left.\mathrm{C}_{2}\right), 2.79(1 \mathrm{H}$ of $\left.\underline{\mathrm{H}}_{2} \mathrm{CO}\right), 3.22\left(3 \mathrm{H}, \mathrm{m}, 1 \mathrm{H}\right.$ of $\underline{\mathrm{C}}_{2} \mathrm{CO}$ and $\left.\mathrm{NC}_{2} \mathrm{CH}_{2}\right), 4.52\left(2 \mathrm{H}, \mathrm{m}, \mathrm{NC}_{2} \mathrm{Ar}\right), 7.68(1 \mathrm{H}$, br., $\operatorname{Ar} \underline{\mathrm{H}}), 7.90(1 \mathrm{H}, \mathrm{br} ., \mathrm{Ar} \underline{\mathrm{H}}), 8.01(1 \mathrm{H}, \mathrm{br} . \mathrm{d}, \mathrm{Ar} \underline{\mathrm{H}})$. To a solution of $27 \mathrm{a}$ in DCM $(2 \mathrm{~mL})$ at $0{ }^{\circ} \mathrm{C}$ was added trifluoroacetic acid $(2 \mathrm{~mL})$. The reaction was stirred overnight, after which time the reaction was washed with saturated sodium bicarbonate solution and extracted with DCM $(3 \times 10 \mathrm{~mL})$. The combined organic layers were dried over anhydrous $\mathrm{Na}_{2} \mathrm{SO}_{4}$, evaporated and purified by flash column chromatography (pet. ether/EtOAc 3:1) to yield the deprotected sulfoxide $13 .{ }^{1} \mathrm{H}-\mathrm{NMR}\left(\mathrm{CDCl}_{3}-\right) \delta_{\mathrm{H}} 0.80\left(3 \mathrm{H}, \mathrm{t}, J=6.7 \mathrm{~Hz}, \mathrm{CH}_{3}\right), 1.19(12 \mathrm{H}$, $\left.\mathrm{m},\left(\mathrm{CH}_{2}\right)_{6}\right), 1.48\left(6 \mathrm{H}, \mathrm{s},\left(\mathrm{CH}_{3}\right)_{2}, 2.54\left(2 \mathrm{H}, \mathrm{t}, J=7.2 \mathrm{~Hz}, \mathrm{NCH}_{2} \mathrm{CH}_{2}\right), 3.17\left(2 \mathrm{H}, \mathrm{s}, \mathrm{CH}_{2} \mathrm{CO}\right)\right.$, $3.85\left(2 \mathrm{H}, \mathrm{s}, \mathrm{NC}_{2} \mathrm{Ar}\right), 7.78(1 \mathrm{H}, \mathrm{d}, J=8.1 \mathrm{~Hz}, \mathrm{Ar} \underline{\mathrm{H}}), 7.95(1 \mathrm{H}, \mathrm{d}, J=7.8 \mathrm{~Hz}, \mathrm{Ar} \underline{\mathrm{H}}), 7.98(1 \mathrm{H}$, s, Ar $\underline{\mathrm{H}}) ;{ }^{13} \mathrm{C}-\mathrm{NMR} \delta_{\mathrm{C}} 14.1\left(\underline{\mathrm{CH}}_{3}\right), 21.1\left(\left(\mathrm{C}_{3}\right)_{2}\right), 22.7,27.3,29.3,29.5,29.9,31.8,49.4,50.6$, $53.0\left(9 \times \mathrm{CH}_{2}\right), 58.7\left(\underline{\mathrm{C}}\left(\mathrm{CH}_{3}\right)_{2}\right), 125.2(\mathrm{Ar} \underline{\mathrm{CH}}), 127.5(\mathrm{Ar} \underline{\mathrm{CH}}), 130.5(\mathrm{Ar} \underline{\mathrm{C}}), 134.7(\mathrm{Ar} \underline{\mathrm{CH}})$, 137.4 (Ar므), $146.5(\operatorname{Ar} \underline{C}), 190.8(\underline{\mathrm{C}}=\mathrm{O})$.

\section{2,2-Dimethyl-6-((octylamino)methyl)thiochroman-4-one 1,1-dioxide (14)}

To a suspension of $26(40 \mathrm{mg}, 0.09 \mathrm{mmol})$ in glacial acetic acid $(10 \mathrm{~mL})$ was added sodium perborate $4 \mathrm{H}_{2} \mathrm{O}(30 \mathrm{mg}, 0.2 \mathrm{mmol})$, in portions. After stirring at $55^{\circ} \mathrm{C}$ for $4 \mathrm{~h}$, the reaction was poured into ice/water $(100 \mathrm{~mL})$. Ethyl acetate was added and the aqueous layer extracted $(3 \times 50 \mathrm{~mL})$. The organic layers were combined, the solvent removed in vacuo and the residue purified by flash chromatography (pet. ether/EtOAc 8:1) to give the BOC-sulfone $27 \mathrm{~b}(33 \mathrm{mg}, 77 \%) .{ }^{1} \mathrm{H}-\mathrm{NMR}\left(\mathrm{CDCl}_{3}\right) \delta_{\mathrm{H}} 0.87\left(3 \mathrm{H}, \mathrm{t}, J=6.8 \mathrm{~Hz}, \mathrm{CH}_{3}\right), 1.26$ (10H, m, $\left.\left(\mathrm{CH}_{2}\right)_{5}\right), 1.37-1.55\left(17 \mathrm{H}, \mathrm{m}, 5 \times \mathrm{CH}_{3}\right.$ and $\left.\mathrm{CH}_{2}\right), 3.14-3.25\left(4 \mathrm{H}, \mathrm{m}, \mathrm{CH}_{2} \mathrm{CO}\right.$ and $\left.\mathrm{NC}_{2} \mathrm{CH}_{2}\right), 4.52\left(2 \mathrm{H}, \mathrm{m}, \mathrm{NC}_{2} \mathrm{Ar}\right), 7.71(1 \mathrm{H}, \mathrm{br} ., \mathrm{Ar} \underline{\mathrm{H}}), 7.95(1 \mathrm{H}, \mathrm{br} ., \mathrm{Ar} \underline{\mathrm{H}}), 8.03(1 \mathrm{H}, \mathrm{d}$, 
$J=8.1 \mathrm{~Hz}, \mathrm{Ar} \underline{\mathrm{H}})$. To a solution of $\mathbf{2 7 \mathrm { b }}$ in DCM $(2 \mathrm{~mL})$ at $0{ }^{\circ} \mathrm{C}$ was added trifluoroacetic acid $(2 \mathrm{~mL})$. The reaction was stirred overnight, after which time the reaction was washed with saturated sodium bicarbonate solution and extracted with DCM $(3 \times 10 \mathrm{~mL})$. The combined organic layers were dried over anhydrous $\mathrm{Na}_{2} \mathrm{SO}_{4}$, evaporated and purified by flash column chromatography (pet. ether/EtOAc 3:1) to yield the deprotected sulfone $14(18 \mathrm{mg}, 69 \%) .{ }^{1} \mathrm{H}-\mathrm{NMR}\left(\mathrm{CDCl}_{3}\right) \delta_{\mathrm{H}} 0.87\left(3 \mathrm{H}, \mathrm{t}, J=6.6 \mathrm{~Hz}, \mathrm{CH}_{3}\right), 1.26\left(12 \mathrm{H}, \mathrm{m},\left(\mathrm{C}_{2}\right)_{6}\right)$, $1.53\left(6 \mathrm{H}, \mathrm{s},\left(\mathrm{CH}_{3}\right)_{2}, 2.64\left(2 \mathrm{H}, \mathrm{t}, J=7.3 \mathrm{~Hz}, \mathrm{NC}_{2} \mathrm{CH}_{2}\right), 3.24\left(2 \mathrm{H}, \mathrm{s}, \mathrm{CH}_{2} \mathrm{CO}\right), 3.95(2 \mathrm{H}, \mathrm{s}\right.$, $\left.\mathrm{NCH}_{2} \mathrm{Ar}\right), 7.87(1 \mathrm{H}, \mathrm{d}, J=8.2 \mathrm{~Hz}, \mathrm{Ar} \underline{\mathrm{H}}), 8.03(1 \mathrm{H}, \mathrm{d}, J=7.9 \mathrm{~Hz}, \mathrm{Ar} \underline{\mathrm{H}}), 8.06(1 \mathrm{H}, \mathrm{s}, \mathrm{ArH})$; ${ }^{13} \mathrm{C}-\mathrm{NMR} \delta_{\mathrm{C}} 14.1\left(\mathrm{CH}_{3}\right), 21.1\left(\left(\mathrm{CH}_{3}\right)_{2}\right), 22.7,27.2,29.2,29.4,29.5,31.8,49.2,50.6,52.7$ $\left(9 \times \underline{\mathrm{CH}_{2}}\right), 58.7\left(\underline{\mathrm{C}}\left(\mathrm{CH}_{3}\right)_{2}\right), 125.2(\mathrm{Ar} \underline{\mathrm{CH}}), 127.7(\mathrm{Ar} \underline{\mathrm{CH}}), 130.6(\mathrm{Ar} \underline{\mathrm{C}}), 134.9(\mathrm{Ar} \underline{\mathrm{C}} \mathrm{H}), 137.7$ (Ar므), $145.5(\operatorname{Ar} \underline{C}), 190.8(\underline{C}=\mathrm{O})$.

\subsection{Bioassay Procedures: Antileishmanial Activity on L. infantum Axenic Amastigotes}

L. infantum promastigotes (MHOM/MA/67/ITMAP-263, CNR Leishmania, Montpellier, France, expressing luciferase activity) were cultivated in RPMI 1640 medium supplemented with $10 \%$ foetal calf serum (FCS), $2 \mathrm{mM}$ L-glutamine and antibiotics (100 U/mL penicillin and $100 \mu \mathrm{g} / \mathrm{mL}$ streptomycin) and harvested in the logarithmic phase of growth by centrifugation at $900 \times g$ for $10 \mathrm{~min}$. The supernatant was carefully removed and replaced by the same volume of RPMI 1640 complete medium at $\mathrm{pH} 5.4$, and then incubated for $24 \mathrm{~h}$ at $24{ }^{\circ} \mathrm{C}$. The acidified promastigotes were then incubated for $24 \mathrm{~h}$ at $37^{\circ} \mathrm{C}$ in a ventilated flask to transform promastigotes into axenic amastigotes. The effects of the tested compounds on the growth of L. infantum axenic amastigotes were assessed as follows. L. infantum amastigotes were incubated at a density of $2 \times 10^{6}$ parasites $/ \mathrm{mL}$ in sterile 96-well plates with various concentrations of compounds dissolved in DMSO (final concentration less than $0.5 \% v / v$ ), in duplicate. Appropriate controls, DMSO and amphotericin, were added to each set of experiments. After a $48 \mathrm{~h}$ incubation period at $37^{\circ} \mathrm{C}$, each plate-well was then microscopically examined to detect any precipitate formation. To estimate the luciferase activity of axenic amastigotes, $80 \mu \mathrm{L}$ of each well were transferred to white 96-well plates, Steady Glow ${ }^{\circledR}$ reagent (Promega, Charbonnières-les-Bains, France) was added according to the manufacturer's instructions, and plates were incubated for $2 \mathrm{~min}$. The luminescence was measured using a Microbeta Luminescence Counter (Perkin Elmer, Villebon-sur-Yvette, France). The inhibitory concentration 50\% ( $\left.\mathrm{IC}_{50}\right)$ was defined as the concentration of drug required to inhibit by $50 \%$ the metabolic activity of $L$. infantum amastigotes compared to control. $\mathrm{IC}_{50}$ values were calculated by non-linear regression analysis on dose response curves, using the TableCurve 2D V5 software (Systat Software, San Jose, CA, USA). IC $_{50}$ values represent the mean of three independent experiments.

\subsection{Cytotoxicity Evaluation on J774A.1 Cells}

Evaluation of the cytotoxicity of test compounds was performed by MTT assay using the J774A.1 cell line (mouse macrophage cell line, Sigma-Aldrich). Briefly, cells $\left(5 \times 10^{4}\right.$ cells $\left./ \mathrm{mL}\right)$ in $100 \mu \mathrm{L}$ of complete medium, [DMEM High glucose supplemented with $10 \%$ fetal calf serum (FCS), $2 \mathrm{mM} \mathrm{L-glutamine}$ and antibiotics $(100 \mathrm{U} / \mathrm{mL}$ penicillin and $100 \mu \mathrm{g} / \mathrm{mL}$ streptomycin)] were seeded into each well of 96-well plates and incubated at $37^{\circ} \mathrm{C}$ in a humidified $5 \% \mathrm{CO}_{2}$ with $95 \%$ air atmosphere. After a $24 \mathrm{~h}$ incubation, $100 \mu \mathrm{L}$ of medium with various product concentrations and appropriate controls were added and the plates were incubated for $72 \mathrm{~h}$ at $37^{\circ} \mathrm{C}$. Each plate-well was then examined under the microscope to detect possible precipitate formation before the medium was aspirated from the wells. $100 \mu \mathrm{L}$ of MTT solution $(0.5 \mathrm{mg} / \mathrm{mL}$ in RPMI) was then added to each well. Cells were incubated for $2 \mathrm{~h}$ at $37^{\circ} \mathrm{C}$. After this time, the MTT solution was removed and DMSO $(100 \mu \mathrm{L})$ was added to dissolve the resulting formazan crystals. Plates were shaken vigorously (300 rpm) for $5 \mathrm{~min}$. The absorbance was measured at $570 \mathrm{~nm}$ with a microplate spectrophotometer. DMSO was used as blank and doxorubicin (Sigma Aldrich, SaintQuentin-Fallavier, France) as positive control. $\mathrm{CC}_{50}$ values were calculated by non-linear regression analysis on dose-response curves, using the TableCurve 2D V5 software. 
Supplementary Materials: The following are available online. NMR spectra of synthesized compounds.

Author Contributions: Conceptualization, J.W.B. and P.d.A.A.; methodology, J.W.B., A.-C.L.L. and S.B.-D.; investigation, J.W.B., S.C., M.A., S.B.-D.; resources, J.W.B. and A.-C.L.L.; data curation, J.W.B.; writing—original draft preparation, J.W.B.; writing—review and editing, J.W.B. and A.-C.L.L.; supervision, J.W.B.; project administration, J.W.B.; funding acquisition, J.W.B. and P.d.A.A. All authors have read and agreed to the published version of the manuscript.

Funding: This research was funded by CAPES-CSF-PVE-S (Programa Pesquisador Visitante Especial) Processo: 88881.064993/2014-01.

Institutional Review Board Statement: Ethical review and approval were not required for this study. Informed Consent Statement: Not applicable.

Data Availability Statement: All data used for the present study has been provided within the Supplementary Materials.

Conflicts of Interest: The authors declare no conflict of interest. The funders had no role in the design of the study; in the collection, analyses, or interpretation of data; in the writing of the manuscript, or in the decision to publish the results.

Sample Availability: Samples of the compounds are available from the authors on request.

\section{References}

1. Maxfield, L.; Crane, J.S. Leishmaniasis. In StatPearls; Internet. StatPearls Publishing: Treasure Island, FL, USA, 2019.

2. Pramanik, P.K.; Alam, M.N.; Roy Chowdhury, D.; Chakraborti, T. Drug Resistance in Protozoan Parasites: An Incessant Wrestle for Survival. J. Glob. Antimicrob. Resist. 2019, 18, 1-11. [CrossRef] [PubMed]

3. Do Nascimento, A.M.; Costa, F.C.; Thiemann, O.H.; de Oliveira, D.C. Chromanones with Leishmanicidal Activity from Calea uniflora. Z. Naturforsch C. 2007, 62, 353-356. [CrossRef] [PubMed]

4. Castro, H.; Cruz, T.; de Aguiar Amaral, P.; da Silva Cardoso, P.; Alsaffar, A.; Farrell, P.; Tomas, A.M.; Barlow, J.W. Synthesis and evaluation of novel chromanone and quinolinone analogues of uniflorol as anti-leishmanial agents. Heliyon 2020, 6, e03614. [CrossRef] [PubMed]

5. Varela, M.T.; Dias, R.Z.; Martins, L.F.; Ferreira, D.D.; Tempone, A.G.; Ueno, A.K.; Lago, J.H.; Fernandes, J.P. Gibbilimbol analogues as antiparasitic agents-Synthesis and biological activity against Trypanosoma cruzi and Leishmania (L.) infantum. Bioorg. Med. Chem. Lett. 2016, 26, 1180-1183. [CrossRef] [PubMed]

6. De Oliveira, A.; Mesquita, J.T.; Tempone, A.G.; Lago, J.H.; Guimarães, E.F.; Kato, M.J. Leishmanicidal activity of an alkenylphenol from Piper malacophyllum is related to plasma membrane disruption. Exp. Parasitol. 2012, 132, 383-387. [CrossRef]

7. Varela, M.T.; Romaneli, M.M.; Lima, M.L.; Borborema, S.E.T.; Tempone, A.G.; Fernandes, J.P.S. Antiparasitic activity of new gibbilimbol analogues and SAR analysis through efficiency and statistical methods. Eur. J. Pharm. Sci. 2018, 122, 31-41. [CrossRef]

8. Zhong, Y.; Han, X.; Li, S.; Qi, H.; Song, Y.; Qiao, X. Design, Synthesis, Antifungal Activity and Molecular Docking of Thiochroman4-one Derivatives. Chem. Pharm. Bull. 2017, 65, 904-910. [CrossRef]

9. Bang, E.J.; Noh, S.G.; Ha, S.; Jung, H.J.; Kim, D.H.; Lee, A.K.; Hyun, M.K.; Kang, D.; Lee, S.; Park, C.; et al. Evaluation of the Novel Synthetic Tyrosinase Inhibitor (Z)-3-(3-bromo-4-hydroxybenzylidene)thiochroman-4-one (MHY1498) In Vitro and In Silico. Molecules 2018, 23, 3307. [CrossRef]

10. Song, J.; Jones, L.M.; Kishore Kumar, G.D.; Conner, E.S.; Bayeh, L.; Chavarria, G.E.; Charlton-Sevcik, A.K.; Chen, S.-E.; Chaplin, D.J.; Trawick, M.L.; et al. Synthesis and Biochemical Evaluation of Thiochromanone Thiosemicarbazone Analogues as Inhibitors of Cathepsin L. ACS Med. Chem. Lett. 2012, 3, 450-453. [CrossRef]

11. Schröder, J.; Noack, S.; Marhöfer, R.J.; Mottram, J.C.; Coombs, G.H.; Selzer, P.M. Identification of Semicarbazones, Thiosemicarbazones and Triazine Nitriles as Inhibitors of Leishmania mexicana Cysteine Protease CPB. PLoS ONE 2013, 8, e77460. [CrossRef]

12. Vargas, E.; Echeverri, F.; Vélez, I.D.; Robledo, S.M.; Quiñones, W. Synthesis and Evaluation of Thiochroman-4-One Derivatives as Potential Leishmanicidal Agents. Molecules 2017, 22, 2041. [CrossRef]

13. Vargas, E.; Echeverri, F.; Upegui, Y.A.; Robledo, S.M.; Quiñones, W. Hydrazone Derivatives Enhance Antileishmanial Activity of Thiochroman-4-ones. Molecules 2018, 23, 70. [CrossRef]

14. Upegui Zapata, Y.A.; Echeverri, F.; Quiñones, W.; Torres, F.; Nacher, M.; Rivas, L.I.; dos Santos Meira, C.; Gedamu, L.; Escobar, G.; Archbold, R.; et al. Mode of action of a formulation containing hydrazones and saponins against leishmania spp. Role in mitochondria, proteases and reinfection process. Int. J. Parasitol. Drugs Drug Resist. 2020, 13, 94-106. [CrossRef]

15. Ortiz, C.; Echeverri, F.; Robledo, S.; Lanari, D.; Curini, M.; Quiñones, W.; Vargas, E. Synthesis and Evaluation of Antileishmanial and Cytotoxic Activity of Benzothiopyrane Derivatives. Molecules 2020, 25, 800. [CrossRef] 
16. Prakash, G.K.S.; Narayanan, A.; Nirmalchandar, A.; Vaghoo, H.; Paknia, F.; Mathew, T.; Olah, G.A. Direct synthesis of 2-/3-(trifluoromethyl)thiochroman-4-ones: Superacid-induced tandem alkylation-cyclic acylation of benzenethiols using 2-/3-(trifluoromethyl)acrylic acid. J. Fluor. Chem. 2017, 196, 63-66. [CrossRef]

17. Vaghoo, H.; Prakash, G.K.S.; Narayanan, A.; Chaudhary, R.; Paknia, F.; Mathew, T.; Olah, G.A. Superelectrophilic Activation of Crotonic/Methacrylic Acids: Direct Access to Thiochroman-4-ones from Benzenethiols by Microwave-Assisted One-Pot Alkylation/Cyclic Acylation. Org. Lett. 2015, 17, 6170-6173. [CrossRef]

18. Clayton, S.E.; Gabbutt, C.D.; Hepworth, J.D.; Heron, B.M. Direct aromatic tert-butylation during the synthesis of thiochroman-4ones. Tetrahedron 1993, 49, 939-946. [CrossRef]

19. Lakouraj, M.M.; Tajbakhsh, M.; Tashakkorian, H. Montmorillonite K10 Catalyzed Selective Oxidation of Sulfides to Sulfoxides Using Hydrogen Peroxide. Lett. Org. Chem. 2007, 4, 75-79. [CrossRef]

20. Page, G.O. The Mild Oxidation of Some Alpha-Difluoro Sulfides to Sulfones with Sodium Perborate. Synth. Commun. 1993, 23, 765-769. [CrossRef]

21. Zhang, C.; Bourgeade Delmas, S.; Fernández Álvarez, Á.; Valentin, A.; Hemmert, C.; Gornitzka, H. Synthesis, characterization, and antileishmanial activity of neutral N-heterocyclic carbenes gold(I) complexes. Eur. J. Med. Chem. 2018, 143, 1635-1643. [CrossRef]

22. Di Pisa, F.; Landi, G.; Dello Iacono, L.; Pozzi, C.; Borsari, C.; Ferrari, S.; Santucci, M.; Santarem, N.; Cordeiro-da-Silva, A.; Moraes, C.B.; et al. Chroman-4-One Derivatives Targeting Pteridine Reductase 1 and Showing Anti-Parasitic Activity. Molecules 2017, 22, 426. [CrossRef] [PubMed]

23. Omolabi, K.F.; Iwuchukwu, E.A.; Odeniran, P.O.; Soliman, M.E.S. Could chroman-4-one derivative be a better inhibitor of PTR1? Reason for the identified disparity in its inhibitory potency in Trypanosoma brucei and Leishmania major. Comput. Biol. Chem. 2021, 90, 107412. [CrossRef] 